\title{
ANÁLISE ECONÔMICA DO EMPREGO DE FERTILIZANTES NAS CULTURAAS DE MILHO E SOJA, NUMA REGIĀO DE CERRADO NO MATO GROSSO DO SUL
}

\author{
MARIA APARECIDA ANSELMO TARSITANO
}

Orientador: Dr. RODOLFO HOFFMANN

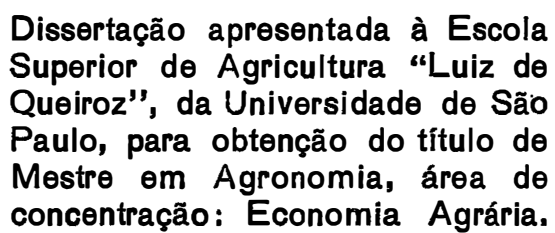

PIRACICABA

Estado de São Paulo - Brasil

Novembro, 1983 
Ao

FERNANDO, DANIEL e RODRIGO pela compreensão e amor a mim dedicados. 
A Universidade Estadual Paulista "Jūlio de Mesquita Filho" pela oportunidade concedida para freqüentar o Cur so de Pós-Graduação.

Ao Professor Rodolfo Hoffmann pela orientação se gura na elaboração deste trabalho, o meu agradecimento especial.

Aos meus pais e aos meus sogros pelo apoio e estímulo durante momentos difíceis do curso.

Aos Professores Evaristo Marzabal Neves e José Ferreira de Noronha, pelas valiosas sugestões oferecidas.

Ao Prof. Zilmar Ziller Marcos e à Srta. Ana Assunção Beltrame pela colaboração prestada.

Aos funcionários da Fazenda Experimental da UNESP campus de Ilha Solteira pelo auxílio na implantação dos ensaios .

Aos professores e colegas do curso pela amizade e convivio. 
LISTA $\mathrm{DE}$ TABELAS $\ldots \ldots \ldots \ldots \ldots \ldots \ldots \ldots \ldots \ldots \ldots \ldots \ldots \ldots \ldots \ldots \ldots$

LISTA DE FIGURAS $\ldots \ldots \ldots \ldots \ldots \ldots \ldots \ldots \ldots \ldots \ldots \ldots \ldots \ldots \ldots \ldots$

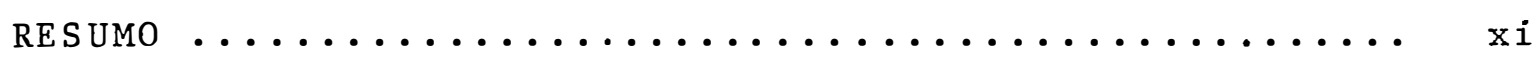

SUMMARY $\ldots \ldots \ldots \ldots \ldots \ldots \ldots \ldots \ldots \ldots \ldots \ldots \ldots \ldots \ldots \ldots \ldots \ldots \ldots \ldots \ldots \ldots$

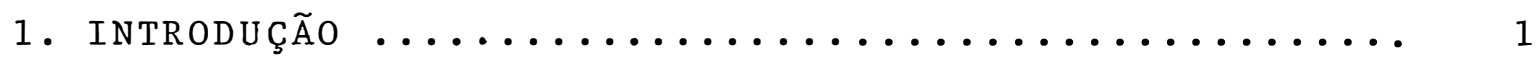

1.1. Importância do Tema .................... 1

1.2. objetivos $\ldots \ldots \ldots \ldots \ldots \ldots \ldots \ldots \ldots \ldots \ldots \ldots$

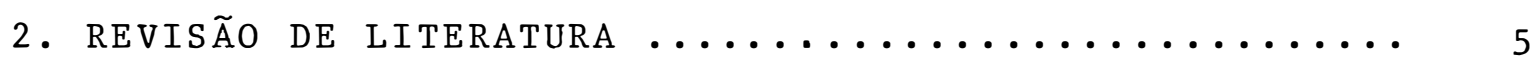

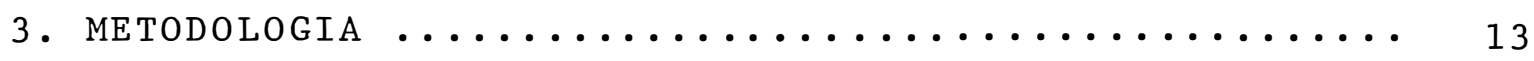

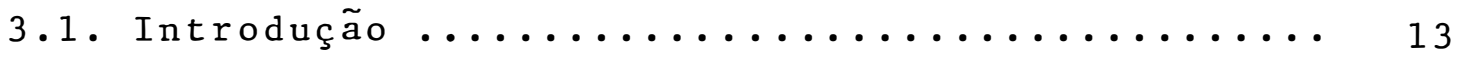

3.2. Aspectos Gerais a Serem Considerados na Implantação de Ensaios de Adubação para Análise Econô

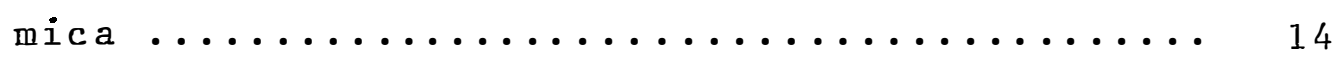

3.3. Variações de Recomendações ................. 19

3.4. Fontes de Dados para Análise Econômica ....... 23 3.4.1. Parte experimental da cultura da soja .. 25 3.4.2. Parte experimental da cultura de milho . 27

3.5. A função de Produção ................. 28

3.5.1. Modelos utilizados nas culturas de milho

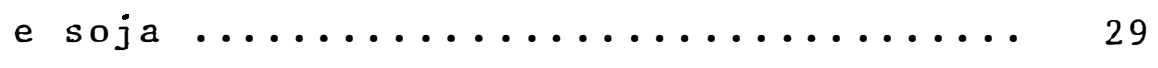

3.5 .1 .1 . Função quadrática ......... 29

3.5.1.2. Função raiz quadrada ....... 33

3.5.1.3. Função de Mitscherlich ...... 34

3.5 .1 .4 . Funções estimadas ........ 35

3.5.2. Variáveis binārias ........... 37 
3.6. Determinação do Nível Economicamente Ōtimo dos

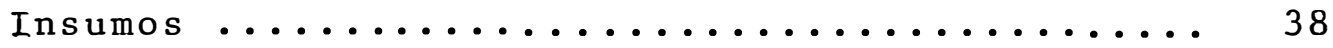

3.7. Determinação do Espaçamento ótimo para a Soja . 41

4. Resultados E discuss 0 ......................... 43

4.1. Análise dos Resultados de Produção ......... 43

4.2. Análise de Regressão ................. 46

4.2.1. Estimativa dos parâmetros e doses econômicas para a cultura de milho ....... 46

4.2.2. Estimativas dos parâmetros e doses econô micas para a cultura da soja ......... 64

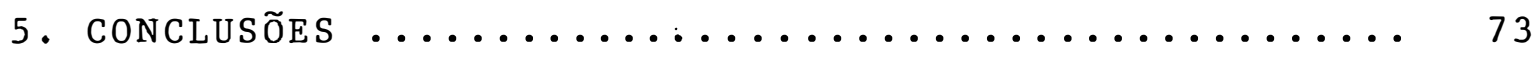

5.1. Considerações sobre a Implantação dos Ensaios de

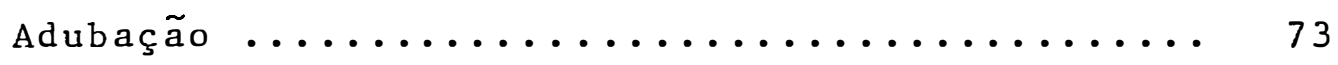

5.2. Conclusões Relativas aos Resultados obtidos nos Experimentos de Milho e Soja .............. 74

5.2 .1 . Milho ....................... 74

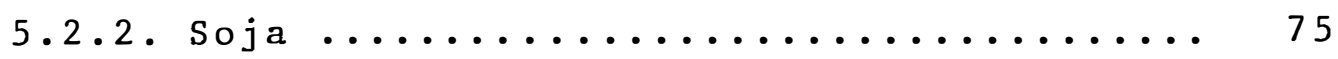

5.2 .3 . Conclusões gerais ............. 76

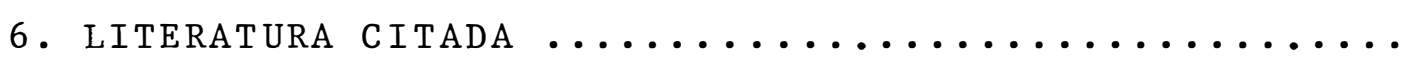


3.1 Dados Pluviométricos e de Temperatura para o

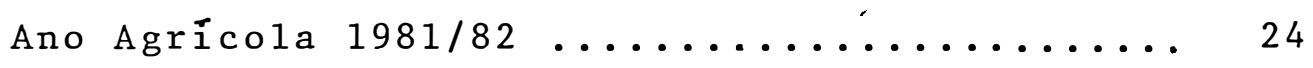

3.2 Resultados das Anālises Químicas do Solo na Ārea Experimental dos Ensaios de Milho e Soja.

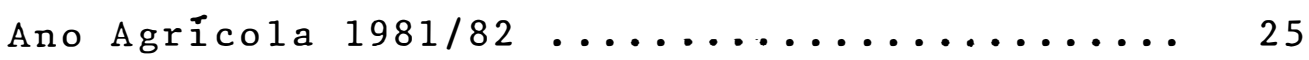

3.3 Tratamentos Utilizados na Cultura da Soja .... 26

3.4 Tratamentos Utilizados na Cultura de Milho em

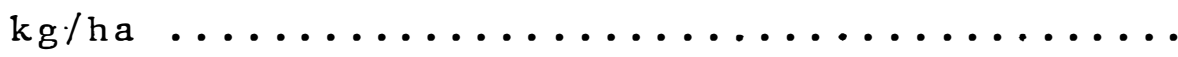

3.5 Valores das Variāveis Binārias Usadas para Dis tinguir os 6 Blocos no Experimento de Milho ..

3.6 Valores das Variáveis Binárias Usadas para Dis tinguir 5 Blocos no Experimento de Soja ..... 38

3.7 Estimativa de Custo Variável de Aplicação de Insumos por Hectare. Ano Agrícola 1981/82 ...

4.1 Resultados Obtidos para a Cultura de Milho com

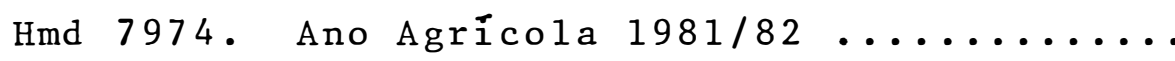

4.2 Resultados Obtidos com o Cultivar Santa Rosa. Ano Agrícola $1981 / 82 \ldots \ldots \ldots \ldots \ldots \ldots \ldots \ldots \ldots \ldots \ldots$

4.3 Resultados Estatísticos das Equações de Regres são Quadrática Ajustadas para a Cultura de Mi1ho, 54 Observações. Ano Agrícola 1981/82 ... 
4.4 Resultados Estatísticos das Equações de Regres são Quadrática Ajustadas para a Cultura de Mi1ho com 27 Observações. Ano Agrícola 1981/82.

4.5 Resultados Estatísticos das Equações de Regres são Quadrática Ajustadas para a Cultura de Mi1ho com 27 observações do Ensaio 1. Ano Agrícola $1981 / 82 \ldots \ldots \ldots \ldots \ldots \ldots \ldots \ldots \ldots \ldots \ldots \ldots \ldots \ldots \ldots \ldots \ldots$

4.6 Resultados Estatísticos das Equações de Regres são Quadrātica Ajustadas para a Cultura de Mi1 ho com 27 observações do Ensaio 2. Ano Agrí-

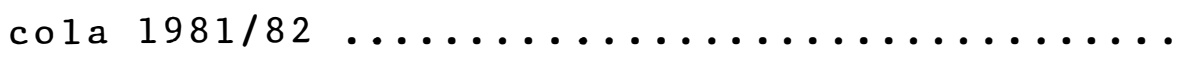

4.7 Resultados Estatísticos das Equações de Regres são Raiz Quadrada Ajustadas para a Cultura de Milho com 27 Observações do Ensaio 1. Ano Agrí cola $1981 / 82 \ldots \ldots \ldots \ldots \ldots \ldots \ldots \ldots \ldots \ldots \ldots \ldots \ldots \ldots \ldots \ldots \ldots$

4.8 Resultados Estatísticos das Equações de Regres são Raiz Quadrada Ajustadas para a Cultura de Milho com 27 Observações do Ensaio 2. Ano Agrị

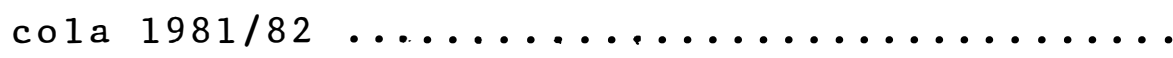

4.9 Resultados Estatísticos da Equação de Mitscher 1ich Ajustada para a Cultura de Milho com 27 Observações do Ensaio 1. Ano Agrícola 1981/82. 
4.10 Resultados Estatísticos da Equação de Mitscher Iich Ajustada para a Cultura de Milho com 27 Observações do Ensaio 2. Ano Agrícola 1981/82

4.11 Estimativa da Dose Econômica de Nitrogênio para o Ensaio 1, Intervalos de Confiança' e Estimativa da Produção ótima, em Milho, para Vārias Relações de Preços. Ano Agrícola 1981/82

4.12 Estimativa da Dose Econômica de Nitrogênio para o Ensaio 2, Intervalos de Confiança e Estimativa da Produção ōtima, em Milho, para Vārias Relações de Preços. Ano Agrícola 1981/82.

4.13 Estimativa da Dose Econômica de Fósforo para o Ensaio 2, Intervalos de Confiança e Estimativa da Produção Ōtima, em Milho, para Vārias Relações de Preços. Ano Agrícola 1981/82 .......

4.14 Estimativa da Dose Econômica de Potássio para o Ensaio 2, Intervalos de Confiança e Estimati va da Produção ōtima, em Milho, para Vārias Re lações de Preços. Ano Agrícola 1981/82 ......

4.15 Resultados Estatísticos das Equações de Regres são Quadrātica Ájustadas para o Ensaio da Soja. Ano Agrícola $1981 / 82 \ldots \ldots \ldots \ldots \ldots$ 
4.16 Estimativas dos Parâmetros das Equações de Regressão Quadrātica Ajustadas para o Ensaio da Soja - Fósforo. Ano Agrícola 1981/82 .......

4.17 Estimativas dos Parâmetros das Equações de Regressão Raiz Quadrada Ajustadas para o Ensaio da Soja - Fósforo. Ano Agrícola 1981/82 ..... 70

4.18 Estimativas dos Parâmetros das Equações de Regressão Mitscherlich Ajustadas para o Ensaio da Soja - Fósforo. Ano Agrícola 1981/82 ..... 71

4.19 Estimativa da Dose Econômica de Fósforo para 60 Observações, Intervalos de Confiança e Esti mativa da Produção ōtima, em Soja, para vārias Relações de Preços. Ano Agrícola 1981/82 .... 
1 Efeito da Deficiência de Zinco nas Respostas de Arroz de Sequeiro e Aplicação de Fósforo

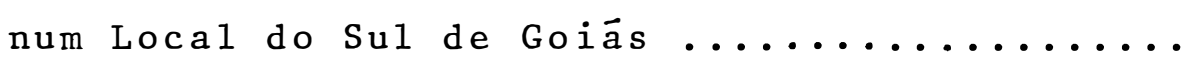

2 Localização da Curva de Produção quando $x_{1}$ é Fixado em värios Níveis .............. 17

3 Representação Grä́ica do Efeito da Adubação nas Variedades Melhorada e Tradicional ......... 


\section{ANĀLISE ECONÔMICA DO EMPREGO DE FERTILIZANTES NAS \\ CULTURAS DE MILHO E SOJA, NUMA REGIÃO DE \\ CERRADO NO MATO GROSSO DO SUL}

Maria Aparecida Anselmo Tarsitano Orientador: Prof.Dr.Rodolfo Hoffmann

RE S UMO

Existe no País uma sērie de pesquisas agronômicas que até hoje não foram interpretadas em termos de recomendações econômicas a nível de produtor. Em parte isto ocorre devido à falta de conhecimentos de técnicas que devam ser apli cadas para transformar os resultados de ensaios de adubação em recomendações apoiadas em princípios econômicos.

Em conseqüência da importância de se realizarem anālises agroeconômicas nos experimentos de adubação resolveu-se, no presente trabalho, discutir alguns critérios que deveriam ser levados em consideração na implantação dos ensaios de adubação a fim de se déterminar um ótimo econômico de produção, a partir de dosagens ótimas de fertilizantes, dada uma relação de preços.

A seguir efetuou-se anāiises agroeconômicas em 2 experimentos de milho e soja em "solos de cerrado" considerando: níveis de adubação $\left(0,40,80,120\right.$ ou $160 \mathrm{~kg} / \mathrm{ha}$ de $\mathrm{P}_{2} \mathrm{O}_{5}$ na 
soja e 20, 80 ou $140 \mathrm{~kg} / \mathrm{ha}$ de $\mathrm{N}$ ou $\mathrm{K}_{2} \mathrm{O}$ e 30,100 ou $170 \mathrm{~kg} / \mathrm{ha}$ de $\mathrm{P}_{2} \mathrm{O}_{5}$ no milho) e diferentes espaçamentos ( 35,40 ou $50 \mathrm{~cm}$ en tre linhas) na soja.

Foram estimadas funções de produção quadrática, raiz quadrada e Mitscherlich e de acordo com as funções estima das, determinadas as quantidades ótimas de nutrientes para diferentes relações de preços.

As principais conclusões do estudo são:

1) Ao planejar experimentos de adubação, os pesquisadores devem se preocupar com a análise química do solo, com o tipo de delineamento experimental a ser utilizado e pro curar repetir os experimentos em mais de um local durante vários anos.

2) Os intervalos de confiança para as doses econômicas dos nutrientes, com base na Variância Assintótica e no Teorema de Fieller na maioria dos casos foram bem discrepantes.

3) A amplitude dos intervalos de confiança basea dos na Variância Assintótica e no Teorema de Fieller, para todos os nutrientes, foi bem menor para o modelo raiz quadrada.

4) Comparando as quantidades ótimas econômicas de $N, P$ e K obtidas com as estimativas das superfícies de produção quadrática, com as obtidas quando se ajustou uma função de produção quadrática para cada nutriente, verifica-se que os resultados são bastante diferentes. Isto se deve aos efeitos 
de interação entre os nutrientes. Entretanto, devido à grande amplitude dos intervalos de confiança, constata-se que aqueles resultados não são, em geral, estatisticamente diferentes.

5) Ao compararmos as quantidades ótimas econômicas de fósforo, obtidas com as estimativas das superficies de produção quadrática, com as estimativas quadráticas obtidas se paradamente para o nutriente, verifica-se que os resultados fo ram semelhantes para a cultura da soja.

6) Os espaçamentos ótimos encontrados para a soja alcançaram valores além dos limites usados no experimento. Sugere-se, deste modo, a montagem de novos experimentos usando-se espaçamentos maiores entre linhas, a fim de verificar se estes resultados são ou não confirmados.

7) A má qualidade dos ajustamentos obtidos não permitiu indicar doses economicamente ótimas confiáveis para todos os nutrientes nas culturas de milho e soja. 
ECONOMIC ANALISYS OF THE USE OF FERTILIZERS IN CORN AND

SOYBEAN IN A "CERRADO" REGION IN MATO GROSSO DO SUL

\author{
Maria Aparecida Anselmo Tarsitano \\ Adviser: Prof.Dr.Rodolfo Hoffmann
}

S UMMARY

There is presently available a significant number of published research papers dealing wiht agronomic problems that are yet to be intepreted from the standpoint of economic recommendations fit to be utilized by the farmer. It is potulated that this situation is partly or totally due to the lack of an economic perspective in the planning and execution of experiments dealing with the aplication of fertilizers. And to test this hypothesis some selected criteria were utilized in the planning and establishment of two field experiments wich yielded data that were submitted to agro-economical analysis. The general procedure followed is outlined below.

A corn and a soybean field experiment were conducted independently in a soil previously under "cerrado" vegetation. The treatments utilized were $0,40,80,120$ and $160 \mathrm{~kg} / \mathrm{ha}$ of $\mathrm{P}_{2} \mathrm{O}_{5}$ in all possible combinations with row spacings of $35 \mathrm{~cm}, 40 \mathrm{~cm}$ and $50 \mathrm{~cm}$ in the soybean experiment. For the corn experiment 
the treatments were 20,80 and $140 \mathrm{~kg} / \mathrm{ha}$ of $\mathrm{both} \mathrm{N}$ and $\mathrm{K}_{2} \mathrm{O}$ and 30,100 and $170 \mathrm{~kg} / \mathrm{ha}$ of $\mathrm{P}_{2} \mathrm{O}_{5}$.

The data collected was analysed to determine the quadratic, square root and Mitscherlich functions. The optimum rate of fertilizer application for each of the crops studied was determined in relation to various price relationships.

The salient conclusions that could be drawn from this study were:

1) Soil chemical analysis data and type of experimental design should be carefully considered prior to the actual execution of the experiment. Experiments should be set in more than one locality and for several years.

2) Other experiments should be conducted considering a wider range of row spacings for soybean in view of the fact that in this study the optimum spacing was found to lie beyond the range considered.

3) Confidence interval for the economic rates, of the various nutrients studied were erratic when calculated on the basis of the assymptotic variance and of Fieller's theorem. The poor quality of these adjustments failed to indicate trustworthy optimum economical rates for all nutrients as related to soybean and $\operatorname{corn}$. 
1. INTRODUÇÃO

1.1. Importância do tema

Um dos aspectos do desenvolvimento agrícola no Brasil tem sido o acréscimo na área cultivada. Isto se deve à existência de uma relativa disponibilidade de terras em regiões novas e aos elevados preços da terra nas regiões tradicionais de cultivo. Nestas regiões, situadas essencialmente no sul do País, tem ocorrido aumentos consideráveis no valor da terra, estimulando o deslocamento de investimentos agrícolas para outras regiões do País.

Entre as regiões do Brasil, o "cerrado" constitui a região de maior potencial na expansão do setor agropecua rio. São mais de 1,5 milhões de $\mathrm{km}^{2}$, ou seja, cerca de $20 \%$ do território nacional, cobertos pela vegetação típica de cerrados. Deste total, $80 \%$ se localizam nos Estados de Minas Gerais, Goiás e Mato Grosso, área geoeconômica para a qual se orientam prioritariamente os esforços e as pesquisas para in- 
corporação do cerrado no processo produtivo (IPEA, 1973).

Neste sentido, o cerrado reüne uma série de qua lidades que o torna bastante atrativo para a implementação de programas de desenvolvimento agropecuārio, devido às vantagens comparativas em termos de preços de terra, possibilidades de expansão em escala da empresa agrícola, por uma relativa proxi midade com os grandes centros consumidores e, em parte, devido à facilidade de mecanização apresentada pelo cerrado.

Esses solos, devido ao seu alto grau de intemperização, têm uma baixa capacidade de troca de cátions que é ocupada na maior parte por íons de hidrogênio e alumínio, do que resulta uma elevada acidez e alta saturação de alumínio. Há uma grande carência de nutrientes e os solos têm uma alta capacidade de adsorver o fósforo na fase sólida, reduzindo a sua disponibilidade na solução, de onde seria absorvido pelas plantas (MIRANDA et alii, 1980).

são vários os trabalhos agronômicos sobre reten ção e disponibilidade de fósforo e sobre teores de outros macro e micronutrientes. No entanto, muitos desses dados não fo ram interpretados em termos de recomendações econômicas a nível de produtor. Uma das razões para essa lamentável situação, talvez seja a falta de conhecimentos das técnicas que devam ser aplicadas para transformar os resultados de ensaios de adubação em recomendações apoiadas em princípios econômicos. Portanto, antes de montar experimentos, os pesquisadores deve- 
rão planejā-los de tal modo que o tipo de delineamento experimental a ser utilizado possibilite tanto a análise estatística como a anālise econômica dos resultados.

A importância de tal estudo vem se acentuando principalmente nos ūltimos anos, quando os preços dos fertilizantes tendem a crescer relativamente mais que os preços dos produtos. Daí a necessidade de os agricultores utilizarem tais insumos eficientemente para minimizarem os custos variáveis por unidade produzida.

Este trabalho tem como finalidade analisar dois experimentos de milho e soja em solo de "cerrado", do ponto de vista agroeconômico considerando: níveis de adubação e diferen tes espaçamentos, com o propósito de obter funções de produção e utilizā-las em anālise econômica.

1.2. Objetivos

os objetivos do estudo são:

a) Discutir alguns aspectos a serem considerados na implantação de ensaios de adubação para fins de análise eco nômica.

b) Estimar funções de produção dos tipos Quadrātica, Raiz Quadrada e Mitscherlich e comparar os resultados com base nas estatísticas obtidas. 
c) Estudar, de acordo com as funções de produção estimadas, as quantidades ótimas econômicas de nutrientes para diferentes relações de preços dos fatores e dos produtos. 
2. REVISÃO DE LITERATURA

o emprego de funções de produção na anāilise e discussão de resultados de experimentos de adubação tem-se constituído em preocupações de diversos autores.

Vários ensaios de adubação para milho e soja têm sido conduzidos em áreas de cerrado com o propósito de transformar seus resultados em recomendações apoiadas em princípios econômicos.

BRITTO et alii (1971) instalaram experimentos de campo num Latossol Vermelho Amarelo sob vegetação de cerrado durante 5 anos. Utilizaram um plano experimental fatorial $3^{3}$, para estudar a influência de vārias combinações de $\mathrm{N}, \quad \mathrm{P}_{2} \mathrm{O}_{5}$ e $\mathrm{K}_{2} \mathrm{O}$ na produção de milho. Os adubos foram aplicados nos 3 pri meiros anos, nos 2 anos seguintes observou-se o efeito residual. A mais alta produção de milho foi obtida com o tratamen to correspondente a $120 \mathrm{~kg} / \mathrm{ha} \mathrm{de}, 60 \mathrm{~kg} / \mathrm{ha} \mathrm{de} \mathrm{P}_{2} \mathrm{O}_{5}$ e.60 $\mathrm{kg} / \mathrm{ha}$ de $\mathrm{K}_{2}$ o. Para confirmação de quais os níveis que realmente se- 
riam ideais para esse tipo de solo, os autores fizeram uma anā 1 ise econômica dos resultados do experimento usando para isto as produções médias dos 3 anos em que houve adubação. A função quadrática ajustada apresentou ponto de sela, visto que, os ter mos quadráticos para nitrogênio e fósforo apresentaram valores positivos. Para existência de máximo é necessārio que os ter mos quadráticos sejam todos negativos. A dose econômica encon trada para o potássio estava muito acima do nível máximo empre gado no trabalho.

Utilizando os mesmos dados experimentais de Brit to, os coeficientes da superfície de resposta quadrática foram reestimados e constatou-se que os coeficientes dos termos quadrāticos são todos negativos, não havendo ponto de sela. Foi utilizada a função quadrática para representar a resposta da produção de milho ao uso de ${ }^{-} N, P$ e $K$, a qual apresentou bom ajustamento em todos ensaios. Além de se usar as produções mé dias dos 3 anos em que houve adubação foi considerada também a média dos 2 últimos anos e do total 5 anos. Em todos esses ca sos foi possível determinar as doses econômicas de $N$, $P$ e K.

MASCARENHAS et ali $i$ (1971) estudaram o efeito da aplicação de doses crescentes de fósforo e potássio sobre a produção de soja, durante 3 anos consecutivos, na região da A $\underline{1}$ ta Mogiana, no Estado de São Paulo. O delineamento experimental adotado foi o fatorial $4^{2}$ onde os níveis de fósforo e potássio pesquisados foram: $0,40,80$ e $120 \mathrm{~kg} / \mathrm{ha}$ de $\mathrm{P}_{2} \mathrm{O}_{5}$ e 0 , 30,60 e $90 \mathrm{~kg} / \mathrm{ha}$ de $\mathrm{K}_{2} \mathrm{O}$, respectivamente. Utilizando a fórmu 
1a desenvolvida por PIMENTEL GOMES e ABREU (1959), para a equa ção Mitscherlich, determinaram as doses econômicas de fósforo para diversas relações de preços. A avaliação dos efeitos resultantes das aplicações das doses mais econômicas de fósforo mostrou retornos do capital investido em fertilizantes da ordem de $145 \%$ e 205\%. No caso do potássio, a menor dose aplicada foi suficiente para aumentar a produção, muito embora sua reação tenha sido fraca se comparada proporcionalmente com a dose zero de $\mathrm{K}_{2} \mathrm{O}$ e, tendencialmente, ter-se mantido constante com o aumento da dosagem de $\mathrm{K}_{2} \mathrm{O}$.

BRAGA et alii (1972) selecionaram 4 locais do Triângulo Mineiro, com a finalidade de estudar a resposta da soja à aplicação de $N, P, K$ e calcário. Os resultados mostraram que não houve efeito do calcário e não houve interação ca cário x tratamentos, mas os efeitos de tratamentos e locais fo ram significativos. Para o estudo econômico, os dados de produção foram utilizados para estimar uma equação quadrática, on de foram analisados os efeitos dos nutrientes para todos os 1o cais em conjunto, obtendo um coeficiente de determinação igual a 0,69. Considerando os preços de $\operatorname{Cr} \$ 0,50 / \mathrm{kg}$ de soja, $\operatorname{Cr} \$$ $1,75 / \mathrm{kg}$ de $\mathrm{N}, \operatorname{Cr} \$ 1,50 / \mathrm{kg}$ de $\mathrm{P}_{2} \mathrm{O}_{5}$ e $\operatorname{Cr} \$ 0,70 / \mathrm{kg}$ de $\mathrm{K}_{2} \mathrm{O}$, as quan tidades econômicas foram de $116 \mathrm{~kg} / \mathrm{ha}$ de $\mathrm{N}, 65 \mathrm{~kg} / \mathrm{ha}$ de $\mathrm{P}_{2} \mathrm{O}_{5}$ e $64 \mathrm{~kg} / \mathrm{ha}$ de $\mathrm{K}_{2} \mathrm{O}$.

Com o objetivo de analisar a resposta do milho à adubação N, P e K, BAHIA et alii (1973) realizaram 23 ensaios no Estado de Minas Gerais. O delineamento experimental adota- 
do foi o fatorial $3^{3}$ com confundimento total da interação $N, P$. e K, grupo W. A anālise de variância e o método de Mitscher1ich foram aplicados na interpretação dos resultados, juntando-se os dados de produção referentes a solos do mesmo grupo. Para o cálculo das doses econômicas dos nutrientes tomaram-se os preços médios dos produtos e dos adubos relativos a 1970 . Os resultados mostraram efeitos altamente significativos para fós foro e nitrogênio, porém, não se verificou nenhum efeito para potássio. No latossol vermelho escuro fase cerrado, a dose eco nômica obtida para o fósforo está de acordo com a que seria re comendada com base na anālise química dos solos. Para o nitro gênio não foi possível a obtenção da dose ótima econômica, enquanto que para o fósforo a dose econômica foi estimada em 111 $\mathrm{kg} / \mathrm{ha}$ de $\mathrm{P}_{2} \mathrm{O}_{5}$

Um fato que nos chama atenção é que no cálculo da dose econômica, foi utilizado o preço médio anual, isto é, a média aritmética dos preços mensais de janeiro a dezembro de 1970. E importante lembrar que, devido às oscilações de preços, não só entre anos como também mensalmente, os preços dos produtos agrícolas apresentam uma grande variabilidade. Isto se deve principalmente à estacionalidade da produção agrícola, pois na época da safra o preço é relativamente baixo, aumentan do depois na época de entre-safra; o que torna suspeita a uti1 ização de preços médios anuais na determinação de doses ótimas econômicas de nutrientes. Diante disso, é recomendável que se trabalhe com diversas relações de preços. Deve-se lembrar 
também que os custos de adubação não incluem apenas o montante pago pelos nutrientes, mas também os custos de transporte e de colocação do adubo no solo.

GUAZELLI et alii (1973) analisaram os rendimentos de soja, feijão e arroz em solos de cerrado, a diversos ní veis de calcário, N, P, K e micronutrientes, através do uso de delinẹmentos fatoriaj.s $2^{n}$. Para avaliação das superfícies de resposta para a soja usaram um esquema fatorial $5^{\mathrm{n}}$. As quanti dades estimadas de calcário e $\mathrm{P}_{2} \mathrm{O}_{5}$ necessários para o rendimen to máximo foram calculadas em 4268 e $323 \mathrm{~kg} / \mathrm{ha}$ respectivamente. Todos estes dados caíram dentro da amplitude dos valores observados dos ensaios. Para determinação das doses econômicas foram ajustadas funções quadrāticas e utilizados preços mé dios de 1968 dos produtos e dos fatores de produção. Usando es tes preços, a produção ótima foi de $1224 \mathrm{~kg} / \mathrm{ha}$ com emprego de $83 \mathrm{~kg} / \mathrm{ha}$ de $\mathrm{P}_{2} \mathrm{O}_{5}$, sem calcário. Por conseguinte, utilizando os preços médios anuais, Guazelli incorre nos mesmos erros já ressaltados na anālise de BAHIA et alii (1973).

Tambēm DUTRA et alii (1975) conduziram ensaios em Goiânia para verificar os efeitos da adubação $N$, $P$ e $K$ na cultura da soja em cerrado. O delineamento utilizado foi um fatorial $3 \times 4 \times 3$ em blocos ao acaso com duas repetições. Os dados de produção analisados estatisticamente mostraram que das causas de variação estudadas, apenas o fósforo mostrou efeito significativo. Na anālise de produção de grãos de soja, o mo- 
delo que melhor se ajustou aos dados foi o de 20 grau, mostran do um coeficiente de determinação igual a 0,51 .

Ainda o mesmo autor analisa os dados de produção de 2 variedades de soja com diferentes níveis de $\mathrm{P}_{2} \mathrm{O}_{5}$ na forma de superfosfato simples. São apresentadas as doses econômicas para vários valores da relação entre preço do fator e preço do produto.

SATURNINO e MORENO (1977) realizaram trabalhos experimentais em 5 municípios das regiões do Triângulo Mineiro e Alto Paraíba. Estes trabalhos buscaram definir, para a soja, os melhores índices de calagem e fosfatagem nos cerrados recém desbravados. Foi ajustada a função quadrática para representar a resposta de produção de soja ao uso de fósforo e calcārio. Estudaram-se as quantidades de fósforo e calcārio economicamente recomendáveis, para a cultura da soja em cerrado recém desbravado, considerando-se os incentivos fiscais of $\underline{\text { e }}$ recidos pelo Polocentro; as taxas internas de retorno ao uso do fósforo e calcário; e os riscos relacionados aosinvestimentos em fósforo e calcário em função de variações no preço da so ja e na quantidade produzida. Dos resultados obtidos, a conclusão geral, dentre outras, é que devido aos incentivos dados através do polocentro, em $90 \%$ dos casos, os retornos à aplicação em altos níveis de corretivos de solo para a cultura da so ja em cerrado são positivos. Porém, quando não se consideram os efeitos dos empréstimos especiais para o cerrado, a correção dos solos deixa de ser economicamente recomendável. 
LOBATO et alii (1978) conduziram experimentos de adubação de milho e soja no Distrito Federal durante o ano de 1966. No experimento de milho foram aplicados 4 níveis de fos fato $\left(0,150,300\right.$ e $450 \mathrm{~kg} / \mathrm{ha}$ de $\left.\mathrm{P}_{2} \mathrm{O}_{5}\right)$ e 3 níveis de calcário $(0,5$ e $10 \mathrm{t} / \mathrm{ha})$. As curvas de resposta de produção föoram cal culadas em função de $\mathrm{P}_{2} \mathrm{O}_{5}$, em níveis variados de calcārio, a fim de se determinar geometricamente o ótimo nível de aplicação de fosfato e a renda bruta após a dedução dos custos do calcário e adubo. Os resultados obtidos foram os seguintes: não se utilizando calcārio, a quantidade economicamente recomendável de $\mathrm{P}_{2}{ }{ }_{5}$ foi $150 \mathrm{~kg} / \mathrm{ha}$, resultando numa renda bruta de Cr\$480,00/ha; nos níveis de 5 a 10 t de aplicação de calcários. a ótima dose de fosfato foi a mesma, porém a renda bruta no ní vel de 5 t de calcārio foi de $\operatorname{Cr} \$ 500,00 /$ ha que è aproximadamente Cr $\$ 100,00$ mais alta do que a renda bruta conseguida no nível de 10 tha de calcário.

um estudo do efeito de 4 doses de fosfato residual num campo de soja. Da mesma forma, a resposta da produção foi calculada em função de $\mathrm{P}_{2} \mathrm{O}_{5}$ residual para determinar a quantidade ótima econômica de $\mathrm{P}_{2} \mathrm{O}_{5}$ residual (150 kg/ha) e a renda bruta apōs de dução dos custos do calcārio e do adubo (Cr\$340,00/ha).

SCOLARI et alii (1982) analisaram o uso de fósfó ro e calcário nas culturas de milho e trigo de sequeiro em solos de cerrado do Brasil Central tendo em vista duas situações: uma de subsídio ao preço dos fatores através das políticas especiais de crédito para a região; outra na qual não se conside 
ram os subsídios. Foram determinadas funções de produção e ta xas de retorno a investimentos nesses elementos. Para se esti mar uma superfície de resposta dessas culturas, foram testados os modelos: raiz quadrada, com expoente $3 / 2$ e quadrático. 0s melhores resultados foram conseguidos com o modelo quadrático.

Uma das conclusões a que chegaram os autores é que a adubação corretiva e a calagem efetuadas em solos de cer rado podem ser viáveis economicamente quando se cultiva milho ou trigo de sequeiro. Quando considerados os preços subsidiados pelos programas especiais de crédito aos fatores e o preço de mercado para o produto, a taxa de retorno em milho a esse investimento foi de $145 \%$. Se considerados os preços de mercado para o fator, a taxa de retorno caiu para $16 \%$ ao ano.

Vale a pena ressaltar que neste trabalho os auto res utilizaram como preço de milho, para determinação da dose ótima econômica do nutriente, o preço médio de mercado dos meses de outubro e novembro. E importante lembrar que não devem ser tomados preços de mercado, sobre os quais já incidem os custos de comercialização, mas os preços médios pagos aos produtores. Além disso, deve-se ressaltar que o preço a ser utilizado no cálculo da dose econômica é o preço na época da safra que, no caso do milho, se dá nos meses de março a maio. 
3. METODOLOGIA

\subsection{Introdução}

Existem no País muitos dados de pesquisa agronômica que até hoje não foram interpretados em termos de recomen dações econômicas a nível de produtor. Essa situação é particularmente comum nos casos de ensaios de adubação. Por exemplo, a partir de 129 ensaios sobre adubação de arroz de seque $\underline{i}$ ro em Goiás, KUSSOW (1976) conseguiu selecionar apenas 21 ensaios para realizar um estudo econômico. Em outras palavras, a aplicação de alguns critérios para realizar tal estudo resul tou numa taxa de rejeição de $86 \%$.

Isto ocorre porque tais trabalhos têm enfatizado aspectos puramente agrcnômicos, e em muitos casos não correlacionam variações nas doses empregadas de fertilizantes com va riações na quantidade de produto obtida. Como conseqüência ve rifica-se que hà grande nümero de experimentos que tềm o seu 
uso limitado pela falta de indicações técnicas economicamente viàveis.

Para,CAMPos (1973) a experimentação deveria ser conduzida de molde a possibilitar a obtenção de funções de pró dução a serem obtidas por unidade de área, variando-se as doses de um ou vārios nutrientes. Conhecidas essas funções e co nhecidos os preços do produto e dos nutrientes, poder-se-iam determinar diversos objetivos econômicos. Este seria um grande passo no sentido de conciliar eficiência técnica com eficiência econômica.

Já existe uma série de trabalhos que tratam de aspectos econômicos da adubação, mas são poucos os que apresen tam os critérios que deveriam ser levados em consideração nos ensaios de adubação para fins de anālise econômica.

3.2. Aspectos Gerais a Serem Considerados na Implantação de Ensaios de Adubação para Anālise Econômica

a) Os dados de cada ensaio devem ser acompanhados por anālises do solo amostrado antes da aplicação do adubo. A produtividade da cultura deve ser limitada somente pelos nutrientes que estão sendo pesquisados e não por qualquer outro nutriente essercial. Por exemplo, no estudo de kUSSOW a influência de zinco na resposta de arroz de sequeiro ao fósforo no mesmo solo, em anos consecutivos, está ilustrada na figura 1 . 


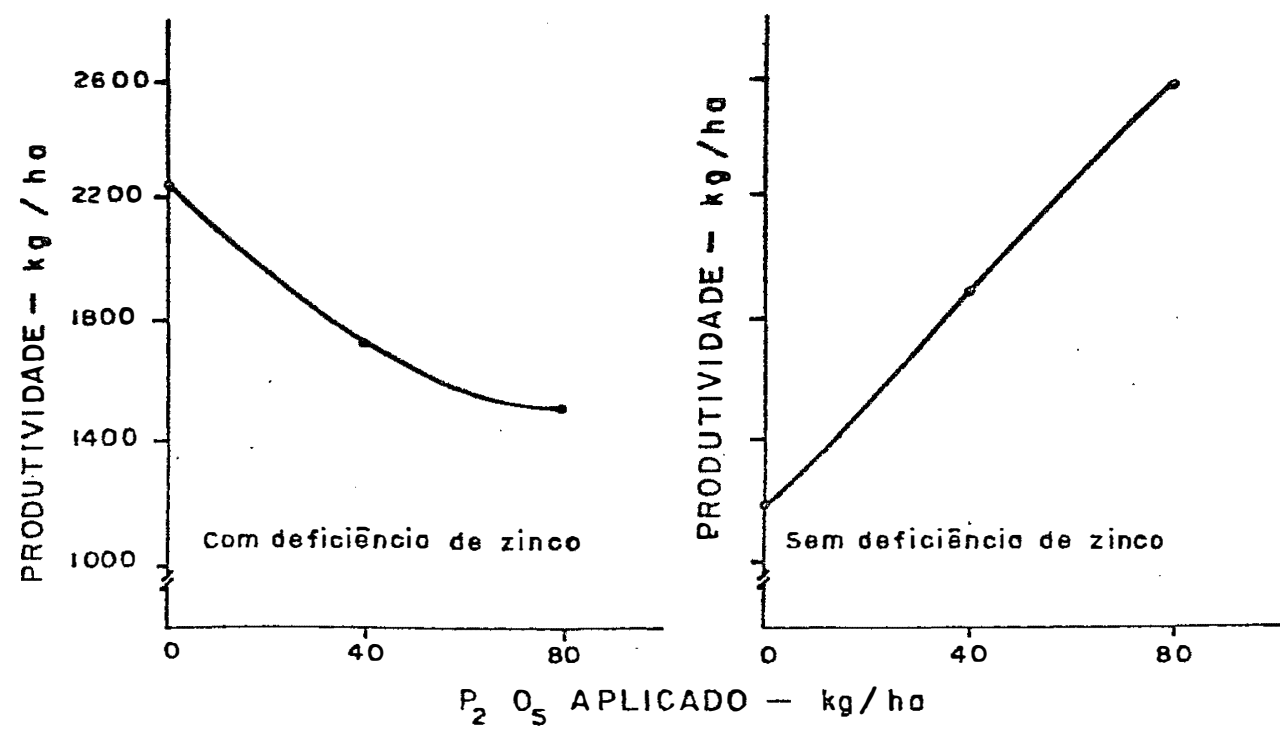

Figura 1 - Efeito da deficiência de zinco nas repostas de arroz de sequeiro e aplicação de fósforo num local do Sul de Goiàs.

Observa-se na figura que, no caso da deficiência de zinco, a aplicação de fósforo acentua esta carência. Não considerando este fato, seria possivel chegar à conclusão errô nea de que neste solo l ppm de fósforo seria suficiente para o arroz de sequeiro.

b) Deve-se procurar aplicar níveis de adubação que englobem doses bastante elevadas sob ponto de vista de ana 
lise do solo. Para que se possa fazer uma recomendação com maior segurança, deve-se evitar problemas com a extrapolação dos resultados.

c) Um outro ponto importante diz respeito ao deIineamento de experimentos de adubação. Neste caso os objetivos do cientista do solo e do economista nem sempre coincidem. Os cientistas de solo em geral escolhem poucos níveis de aduba ção, fazendo vārias repetições de cada nível para obter melhor estimativa do erro experimental. Trata-se de delineamentos orientados à anālise de variância. Porém a anālise de variância somente diz se as observações dos tratamentos dão "diferen ças significativas" entre os níveis ou não.

No entanto, para estimação de superfície de resposta, uma grande amplitude de observações sobre a superfície é mais útil para se determinar a localização da curva ou super fície do que muitas observações sobre somente três pontos da superfície (figura 2).

Dada a escassez de recursos para pesquisa, os cientistas de solo e economistas devem trabalhar juntos no pla nejamento dos experimentos. 

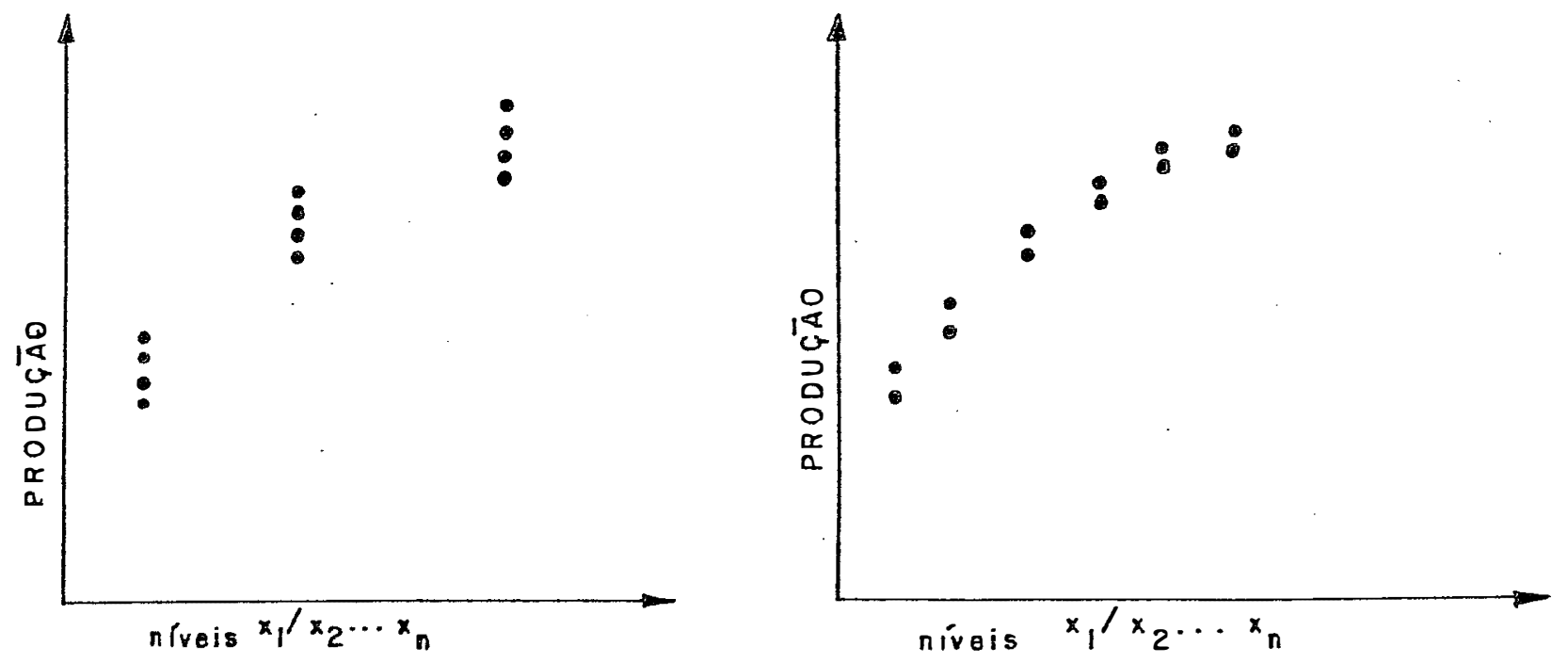

Figura 2 - Localização da curva de produção quando $x_{1}$ é fixado em värios níveis.

d) Variedades diferentes apresentam respostas vạ riáveis ao tratamento com fertilizantes. Alguns resultados ex perimentais indicam que as variedades melhoradas quando cultivadas sem aplicação de fertilizantes podem apresentar rendimen to menor do que as variedades tradicionais (figura 3 ).

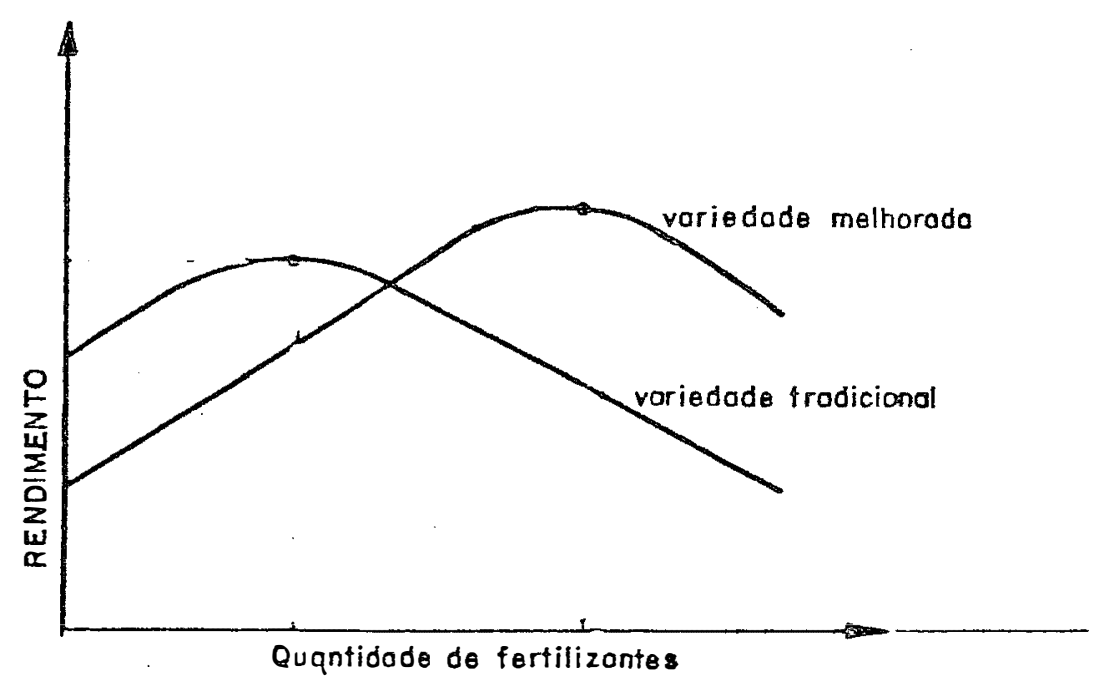

Figura 3 - Representação gráfica do efeito da adubação nas variedades melhorada e tradicional. 
A resposta do efeito da adubação é muito maior na variedade melhorada à medida que se aumenta a quantidade de fertilizantes, o mesmo não ocorrendo com a variedade tradiciona1.

e) Os resultados de produção devem apresentar bai xa dispersão relativa. O coeficientede variação sendo uma me dida da dispersão relativa ou da concentração de uma distribui ção, dá uma idéia da precisão do experimento. Quanto mais ba xo o coeficiente de variação melhor foi conduzido o experimento.

f) Quando se deseja analisar economicamente os resultados experimentais, a aplicabilidade das conclusões obti das, deve constituir-se no objetivo principal. Portanto, ao planejar um experimento, deve-se verificar que existem variações de resposta que podem ocorrer de uma época para outra e de um lugar para outro, em virtude das variações dos tipos de solos, diferenças climáticas, etc. Resulta deste fato a neces sidade de repetir os experimentos em mais de um lugar, durante vários anos e várias estações quando for o caso.

Segundo CAMpos (1967), quando se analisa um único experimento é comum o aparecimento de ponto de sela, por ís so não se consegue determinar a dose ótima econômica do nutriente. Há maior tendência de aparecimento de ponto máximo à medida que se procede ao agrupamento dos ensaios. Isto se juㅗ tifica pela maior precisão nas médias dos tratamentos. 
g) Este ültimo ponto relaciona-se com as questões de risco e. incerteza. Muitas vezes faz-se, implicitamente, a pressuposição de que o agricultor tem conhecimento perfeito não apenas sobre a função de produção, mas também sobre os preços do seu produto e seus insumos. Porém, não é isto que acontece. Os rendimentos variam muito de um ano para outro, dependendo das condições climáticas e o agricultor sempre trabalhará em função de expectativas de preços. Uma decisão errada pode apresentar grandes conseqüências.

3.3. Variações de Recomendações

Apesar dos dispendiosos esforços feitos para aumentar o uso de fertilizantes, não se tem clareza sobre quais são as doses econômicas nas diversas situações. Os resultados obtidos da análise de experimentos são freqüentemente inconclu síveis ou até contraditórios.

Hā vārios problemas que podem causar variações de recomendações de dose econômica, baseados nos mesmos ensaios experimentais:

a) Preço do produto

Não se deve tomar os preços de mercado, sobre os quais já incidem os custos de comercialização, mas os preços médios pagos aos produtores. VIEIRA (1980) assinala que dos preços médios pagos aos produtores deve-se subtrair os custos variáveis de colheita por unidade do produto. 
A função de renda líquida é definida como segue:

$$
\pi=P_{y} Y-P_{x} X-C-H Y=\left(P_{y}-H\right) Y-P_{x} X-C
$$

onde: $\pi$ = renda líquida

$$
\begin{aligned}
\mathrm{Y}= & \text { quantidade produzida do produto } \\
\mathrm{X}= & \text { quantidade de nutriente, em kg/ha } \\
\mathrm{P}_{\mathrm{y}}= & \text { preço unitário do produto pago ao produtor } \\
\mathrm{P}_{\mathrm{X}}= & \text { preço unitāio do nutriente, incluindo custos variá- } \\
& \text { veis de aplicação do mesmo } \\
\mathrm{C}= & \text { custos fixos } \\
\mathrm{H}= & \text { custos variāveis de colheita por unidade do produto. }
\end{aligned}
$$

A condição necessária para que a receita líquida seja máxima é que a derivada de $\pi$ com relação a X seja igual a zero.

$$
\begin{aligned}
& \frac{d Y}{d X}\left(P_{y}-H\right)=P_{X} \\
& \frac{d Y}{d X}=\frac{P_{X}}{P_{y}-H}
\end{aligned}
$$

Se o custo de colheita de um determinado produto é variável, deve-se subtrai-lo dos preços médios pagos aos pro dutores.

b) Custo de adubação

- Os custos de adubação devem incluir além do montante pago pelos nutrientes, os custos de aplicação do mesmo 
no solo. Além disso, deve-se considerar o capital empatado na adubação, que deve ser acrescido dos juros correspondentes ao período decorrido entre a colocação do adubo no solo e a co1heita, porque só existe retorno por ocasião da colheita. Finalmente, é necessārio descontar desse total os subsídios rece bidos na compra do adubo. 0 custo de adubação assim obtido de ve ser então dívidido pela quantidade de nutriente, para obter o preço do nutriente para o produtor (ver, por exemplo, VIEIRA, $1980)$.

Devemos lembrar que os preços são variāveis não só entre anos como também mensalmente e que estimamos quantidạ des econômicas igualando o produto físico marginal à relação de preços, definida pelo quociente entre preço do nutriente e. preço do produto. Para que essas doses econômicas possam ser usadas em anos subseqüentes, é recomendável que se apresente uma tabela onde se considerem diversas relações de preços.

c) Condições Experimentais

As estações experimentais normalmente dispõem de uma série de fatores favorāveis que permitem obter bons resultados, os quais não são facilmente duplicāveis ao nível das propriedades rurais. As condições experimentais sob as quais as funções de produção são estimadas em geral não são representativas das condições em que a cultura é conduzida nas fazendas. As técnicas a serem utilizadas devem ser as mesmas ou parecidas com as do agricultor. 
d) 0 tipo de função ajustada

Há um grande número de equações que podem expres sar uma função de produção.

o tipo de função escolhida, dependendo da sua for ma e das observações, pode também levar ao cálculo de diferentes "pontos ótimos".

A escolha do modelo matemático de uma função de produção, segundo VIEIRA (1980), deve levar em consideração a guns aspectos caracteristicos do problema. Tais modelos devem ser ajustados aos dados experimentais para posterior seleção do melhor modeio em função de estatísticas obtidas.

A mesma autora considera que, se dois ou mais nu trientes são estudados no mesmo experimento, devemos primeiro verificar, através de uma anālise de variância, se existem interações significantes entre nutrientes. Se as interações não são significantes é razoāvel ajustar uma função de produção pa ra cada nutriente. A computação é mais fácil e a literatura mostra que quantidades de nutrientes obtidas dessa forma são análogas àquelas obtidas através de funções cujos modelos incluem todos os nutrientes. ${ }^{1}$

Existem casos tambēm em que a estimativa da quan tidade econômica de nutrientes apresenta sinal negativo. Nessas situações, o critério razoável é recomendar não adubar.

1 Deve-se assinalar que tambëm se pode argumentar no sentido de sempre deixar as interações no modelo, pois um teste não-significavo não garante que o parâmetro $\bar{e}^{3}$ nulo. 
3.4. Fontes de Dados para Anāiise Econômica

Tendo em vista o objetivo proposto, foi escolhida uma ärea no campus de IIha Solteira, localizada no município de Selvíria, Estado de Mato Grosso do Sul.

O clima dessa região é caracterizado por apresen tar de um modo geral, temperaturas altas. A média mensal das temperaturas māximas diārias varia de $290 \mathrm{C}$ a $319 \mathrm{C}$ e a média men sa 1 das temperaturas mínimas diārias varia de $179 \mathrm{C}$ a $229 \mathrm{C}$ durante o ano.

A precipitação anual è de aproximadamente $1300 \mathrm{~mm}$ e varia de $1000 \mathrm{~mm}$ a $1500 \mathrm{~mm}$. Aproximadamente $80 \%$ destas chuvas acontecem no período de outubro a março. O período mais seco vai de abril a setembro, quando a precipitação é de $200 \mathrm{~mm}$. Os dados pluviométricos e de temperatura para o ano agrícola 1981/ 182 estão na tabela 1 .

Os tipos de solos encontrados no campus de Ilha Solteira são o Latossol Vermelho Escuro e o Latossol Verme1ho Amarelho, os quais, segundo FREITAS e SILVEIRA (1977), são os que devem ser estudados cuidadosamente e nos quais devem ser realizados trabalhos de experimentação, por serem os que apresentam melhores condições para o desenvolvimento de uma agricultura com a1to níve1 tecnológico.

Esses tipos de solos apresentam, em condições na turais, baixo pH, alta saturação de alumínio e baixo conteūdo 
de cälcio e magnēsio. Segundo o Relatōrio Técnico Anual 76 da EMBRAPA, aqueles dois tipos de solo abrangem $52 \%$ das áreas do cerrado.

A topografia suavemente ondulada permite que o manejo desse solo seja efetuado mecanicamente, favorecendo a adoção de tecnologias modernas.

Tabela 3.1 - Dados pluviométricos e de temperatura para o ano agrícola $1981 / 82$.

\begin{tabular}{|c|c|c|c|c|}
\hline \multirow{2}{*}{ Meses } & \multicolumn{2}{|c|}{ Chuvas } & \multicolumn{2}{|c|}{ Temperaturas mëdias $\left({ }^{\circ} \mathrm{C}\right)$} \\
\hline & Total (mm) & Dias (no) & Māxima & Mínima \\
\hline Outubro & 116,8 & 10 & 30,3 & 20,1 \\
\hline Novembro & 191,1 & 13 & 31,5 & 22,5 \\
\hline Dezembro & 196,2 & 15 & 30,2 & 21,7 \\
\hline Janeiro & 121,8 & 9 & 29,9 & 21,8 \\
\hline Fevereiro & 83,5 & 10 & 30,3 & 21,5 \\
\hline Março & 397,8 & 12 & 29,3 & 21,9 \\
\hline Abril & 36,2 & 3 & 28,7 & 19,0 \\
\hline Maio & 72,8 & 5 & 26,8 & 16,9 \\
\hline
\end{tabular}

Antes da instalação dos ensaios o solo foi anali sado quimicamente e os resultados obtidos se encontram expressos na tabela 3.2. Além de o pH do solo estar baixo (o ideal seria em torno de 6), os valores encontrados para o fósforo e potāssio se situam na faixa de médio. 
Tabela 3.2 - Resultados das análises químicas do solo na área experimental dos ensaios de milho e soja. Ano agrícola $1981 / 82$.

\begin{tabular}{lcccccc}
\hline Ensaio $\% \mathrm{C}$ & $\frac{\mathrm{pH}}{\mathrm{H}_{2} \mathrm{O}}$ & $\frac{\mu \mathrm{g} / \mathrm{ml} \text { de T.F.S.A. }}{\mathrm{P}}$ & $\mathrm{K}$ & & \multicolumn{2}{c}{ emg/100ml de T.F.S.A. } \\
\hline milho 0,9 & 4,5 & 7 & 70 & & 0,4 & 2,9 \\
soja 1,2 & 4,6 & 13 & 64 & 0,5 & 2,7 \\
\hline
\end{tabular}

Os experimentos foram instalados no ano agrícola $1981 / 82$ e as cultivares utilizadas na implantação dos ensaios de milho e soja no cerrado foram respectivamente Hmd 7974 e San ta Rosa.

\subsubsection{Parte experimental da cultura da soja}

Usou-se para o ensaio da soja o delineamento experimental em 5 blocos casualizados, com parcelas subdivididas. A área ocupada por subparcela foi de $30 \mathrm{~m}^{2}$, dando para um bloco a ärea de $600 \mathrm{~m}^{2}$ e para o experimento $4.000 \mathrm{~m}^{2}$.

Nos tratamentos principais foram estudados 3 diferentes espaçamentos: 35,40 e $50 \mathrm{~cm}$ entre linhas. Como subtratamentos foram utilizados níveis de $0,40,80,120$ e 160 $\mathrm{kg} / \mathrm{ha}$ de $\mathrm{P}_{2} \mathrm{O}_{5}$. 
Tabela 3.3 - Tratamentos utilizados na cultura da soja.

\begin{tabular}{cccc}
\hline $\begin{array}{c}\text { Niveis de } \mathrm{P}_{2} \mathrm{O}_{5} \\
(\mathrm{~kg} / \mathrm{ha})\end{array}$ & $\begin{array}{c}\text { Espaçamento } \\
\text { (cm entre } \\
\text { linhas) }\end{array}$ & $\begin{array}{c}\text { Niveis de } \mathrm{P}_{2} \mathrm{O}_{5} \\
(\mathrm{~kg} / \mathrm{ha})\end{array}$ & $\begin{array}{c}\text { Espaçamento } \\
\text { (cm entre } \\
\text { 1inhas) }\end{array}$ \\
\hline 0 & 35 & 80 & 50 \\
0 & 40 & 120 & 35 \\
0 & 50 & 120 & 40 \\
40 & 35 & 120 & 50 \\
40 & 40 & 160 & 35 \\
40 & 50 & 160 & 40 \\
80 & 35 & 160 & 50 \\
80 & 40 & & \\
\hline
\end{tabular}

A fonte de $\mathrm{P}_{2} \mathrm{O}_{5}$ utilizada foi superfosfato simples ( $20 \%$ de $\mathrm{P}_{2} \mathrm{O}_{5}$ ) no sulco de plantio. Esses tratamentos foram repetidos em 5 blocos. Verifica-se que o experimento tinha um total de 75 șubarcelas.

A aplicação de adubo foi efetuada nos dias 10 e 11 de dezembro de 1981, dois dias antes do plantio.

Todas as parcelas receberam no plantio uma aduba ção básica sem fósforo que incluiu nitrogênio (100 kg/ha como sulfato de amônia), potássio (133 kg/ha como cloreto de potássio) e micronutrientes ( $40 \mathrm{~kg} / \mathrm{ha}$ de FTEBR-9). 
3.4.2. Parte experimental da cultura de milho

O delineamento experimental utilizado para o miTho foi em blocos ao acaso, obedecendo ao esquema fatorial $3^{3}$ para $N, P$ e $K$, com confundimento de $2 \mathrm{GL}$ da interação tripla pe 1o modo designado por Yates como W.

Os 27 tratamentos foram distribuidos em 3 blocos incompletos, com 9 parcelas cada um. Como havia 2 repetições dos 27 tratamentos, o ensaio tinha um total de 6 blocos. os 3 níveis de $\mathrm{N}$ e $\mathrm{K}_{2} \mathrm{O}$ utilizados são 20,80 e $140 \mathrm{~kg} / \mathrm{ha}$ e os 3 níveis de $\mathrm{P}_{2} \mathrm{O}_{5}$ são 30,100 e $170 \mathrm{~kg} / \mathrm{ha}$.

Tabela 3.4 - Quantidades de $\mathrm{N}, \mathrm{P}_{2} \mathrm{O}_{5}$ e $\mathrm{K}_{2} \mathrm{O}$, em $\mathrm{kg} / \mathrm{ha}$, nos 27 tra tamentos do experimento com a cultura de milho.

\begin{tabular}{rrrrrrrrr}
\hline $\mathrm{N}$ & $\mathrm{P}_{2} \mathrm{O}_{5}$ & $\mathrm{~K}_{2} \mathrm{O}$ & $\mathrm{N}$ & $\mathrm{P}_{2} \mathrm{O}_{5}$ & $\mathrm{~K}_{2} \mathrm{O}$ & $\mathrm{N}$ & $\mathrm{P}_{2} \mathrm{O}_{5}$ & $\mathrm{~K}_{2} \mathrm{O}$ \\
\hline 20 & 30 & 20 & 80 & 30 & 20 & 140 & 30 & 20 \\
20 & 30 & 80 & 80 & 30 & 80 & 140 & 30 & 80 \\
20 & 30 & 140 & 80 & 30 & 140 & 140 & 30 & 140 \\
20 & 100 & 20 & 80 & 100 & 20 & 140 & 100 & 20 \\
20 & 100 & 80 & 80 & 100 & 80 & 140 & 100 & 80 \\
20 & 100 & 140 & 80 & 100 & 140 & 140 & 100 & 140 \\
20 & 170 & 20 & 80 & 170 & 20 & 140 & 170 & 20 \\
20 & 170 & 80 & 80 & 170 & 80 & 140 & 170 & 80 \\
20 & 170 & 140 & 80 & 170 & 140 & 140 & 170 & 140 \\
\hline
\end{tabular}


As fontes de nutrientes foram: sulfato de amônia para $N$, cloreto de potássio para $K_{2} \mathrm{O}$ e superfosfato simples pa ra $\mathrm{P}_{2} \mathrm{O}_{5}$. A aplicação dos adubos foi efetuada dia 8 de novembro de 1981, um dia antes do plantio em sulcos.

Devido a jā constatada deficiência de micronutrientes em regiões de cerrado, todos os tratamentos receberam no plantio uma adubação bāsica de $40 \mathrm{~kg} / \mathrm{ha}$ de FTEBR-9.

A unidade experimental constitui-se de 6 linhas de $8 \mathrm{~m}$ com espaçamento de $0,90 \mathrm{~m}$. A área ocupada por parcela foi de 43,2 $\mathrm{m}^{2}$, dando para um bloco a área de $389 \mathrm{~m}^{2}$ e para o experimento $3.000 \mathrm{~m}^{2}$.

Com base na anāise do solo, nos dois ensaios foi aplicado o calcārio dolomítico a lanço à razão de 3 t/ha, dois meses antes do plantio.

\subsection{A Função de Produção}

A função de produção consiste de uma relação téc nica entre os fatores envolvidos em um processo produtivo qual quer e a produção máxima possível de se obter quando se combinam esses fatores em formas alternativas.

Inūmeros modelos estatístico-matemāticos têm sido sugeridos para obter estimativas de funções de produção. 0 tipo de equação a ser ajustada aos dados experimentais constitui uma dificuldade, pois qualquer que seja a equação escolhida esta apresenta restrições e afeta as doses econômicas que serão obtidas. 
Os modelos de funções de produção que estudaremos são a quadrática, raiz quadrada e a Mitscherlich.

3.5.1. Modelos utilizados nas Culturas de Milho e Soja

3.5.1.1. Função quadrática

A função quadrātica é utilizada por um grande nü mero de pesquisadores em ensaios de adubação, por permitir que se atinja um ponto de máximo e apresentar características mais consistentes com o mundo real.

A função quadrática também è mais fácil de ser trabalhada matematicamente do que outros tipos de função, prín cipalmente quando há mais de uma variável independente envolvida.

Segundo WRIGHT (1973), a função quadrática apresenta as seguintes vantagens:

- possui um intercepto que pode ter valores posi tivos permitindo a estimação do nível de produção, por unidade de ārea, na ausência de adubação;

- representa o segundo e o terceiro estágios de produção;

- permite a anālise dos efeitos de interação entre nutrientes;

- separa os efeitos lineares e curvilíneos das variāveis independentes. 
A função quadrática também apresenta desvantagens sendo que, dentre as mais sérias, relaciona-se:

- a possibilidade de correlação elevada entre os termos lineares, os termos quadráticos e os termos de interação com outras variáveis (esse problema é mais sério quando os dados não são experimentais);

- a representação do produto marginal como decrescente a uma taxa constante;

- quando comparada com a função de produção CobbDouglas, gasta rapidamente os graus de liberdade com os acréscimos de variáveis independentes no modelo.

Inicialmente serão ajustadas superfícies de produção quadrática aos dados dos ensaios de milho e soja. Para a cultura de milho temos:

$$
\begin{aligned}
y= & \alpha+\beta_{1} x_{1}+\beta_{2} x_{2}+\beta_{3} x_{3}+\beta_{11} x_{1}^{2}+\beta_{22} x_{2}^{2}+\beta_{33} x_{3}^{2}+ \\
& +\beta_{12} x_{1} x_{2}+\beta_{13} x_{1} x_{3}+\beta_{23} x_{2} x_{3}+E
\end{aligned}
$$

onde: $\mathrm{Y}=$ produção de milho em $\mathrm{kg} / \mathrm{ha}$

$$
\begin{aligned}
\alpha= & \text { termo constante } \\
\beta_{1} \ldots \beta_{23}= & \text { coeficientes de regressão } \\
\mathrm{X}_{1}= & \text { doses de nitrogênio por hectare, isto é, } \mathrm{X}_{1}=(\mathrm{N}+40) / 60, \\
& \text { onde } \mathrm{N} \overline{\mathrm{e}} \text { a quantidade de nitrogênio, em } \mathrm{kg} / \mathrm{ha} \\
\mathrm{X}_{2}= & \text { doses de } \mathrm{P}_{2} \mathrm{O}_{5} \text { por hectare, isto é, } \mathrm{X}_{2}=(\mathrm{P}+40) / 70, \\
& \text { onde } \mathrm{P} \overline{\mathrm{e}} \text { a quantidade de } \mathrm{P}_{2} \mathrm{O}_{5}, \text { em } \mathrm{kg} / \mathrm{ha}
\end{aligned}
$$


$\mathrm{x}_{3}=$ doses de $\mathrm{K}_{2} \mathrm{O}$ por hectare, isto é, $\mathrm{x}_{3}=(\mathrm{K}+40) / 60$, onde $\mathrm{K} e \bar{e}$ a quandidade de $\mathrm{K}_{2} \mathrm{O}$, em $\mathrm{kg} / \mathrm{ha}$

E: = erros aleatórios independentes com média zero e variância $\left(\sigma^{2}\right)$ constante.

Para a cultura da soja apresenta a seguinte for-

ma :

$$
Y=\alpha+\beta_{1} X_{1}+\beta_{2} X_{2}+\beta_{11} X_{1}^{2}+\beta_{22} X_{2}^{2}+\beta_{12} X_{1} X_{2}+E
$$

onde: $Y=$ produção de soja em $\mathrm{kg} / \mathrm{ha}$

$$
\begin{aligned}
\alpha & =\text { termo constante } \\
\beta_{1} \ldots \beta_{12} & =\text { coeficientes de regressão } \\
\mathrm{X}_{1} & =\text { doses de } \mathrm{P}_{2} \mathrm{O}_{5} / \mathrm{ha}, \text { isto é, } \mathrm{X}_{1}=\frac{\mathrm{P}}{40} \\
\mathrm{X}_{2} & =\frac{\mathrm{E}-35}{5}, \text { onde } \mathrm{E}=\text { espaçamento entre linhas em } \mathrm{cm} \\
\mathrm{E}: & =\text { erros. }
\end{aligned}
$$

Espera-se encontrar as estimativas dos coeficien tes dos termos lineares positivos e dos termos quadráticos negativos. O fato de o termo quadrático ser negativo indica que a lei dos rendimentos marginais decrescentes se fez presente. Assim, na medida em que doses adicionais de nutrientes são apli cadas, a resposta em termos de produção adicional é cada vez menor (ver, por exemplo, SCHUH e TOLLINI, 1972).

$$
\text { ZAGATTO e PIMENTEL GOMES (1967) fizeram referên- }
$$
cia à aplicação da regressão polinomial do 29 grau, para mais de uma variável independente, citando algumas medidas para sa- 
nar as dificuldades que apareceriam com o seu emprego. As medidas são:

- usar sempre grupos de ensaios numerosos ou iso lados com vārias repetições e boa precisão;

- calcular sempre intervalo de confiança para as doses ótimas, de maneira a possibilitar o julgamento de seu real valor;

- verificar sempre se os valores obtidos correspondem realmente ao māximo;

- não confiar em doses ótimas obtidas a partir do polinômio de 29 grau, no qual os termos quadráticos não tenham sido significativamente diferentes de zero.

Ressalte-se que as três primeiras observações são vālidas independentemente do modelo de regressão utilizado.

Ajustar-se-̄a tambēm (separadamente), uma função quadrática para cada tipo de nutriente:

$$
Y=\alpha+\beta_{1} X+\beta_{11} X^{2}+E
$$

onde: $Y=$ produção de milho (soja) em $\mathrm{kg} / \mathrm{ha}$

$$
\begin{aligned}
\alpha & =\text { termo constante } \\
X & =\text { doses de nitrogênio, } \mathrm{P}_{2} \mathrm{O}_{5} \text { ou } \mathrm{K}_{2} \mathrm{O} \text { por hectare } \\
\beta_{1} \text { e } \beta_{11} & =\text { coeficientes de regressão } \\
E ; & =\text { erros. }
\end{aligned}
$$


São especificados, a seguir, os valores de $X$ em cada caso, indicando por $N, P$ e K as quantidades aplicadas de nitrogênio, $\mathrm{P}_{2} \mathrm{O}_{5}$ e $\mathrm{K}_{2} \mathrm{O}$, em kg/ha. Para a cultura de milho, con forme o nutriente considerado, tem-se

$$
x=\frac{N-20}{60}, \quad x=\frac{P-30}{70} \quad \text { ou } \quad x=-\frac{K-20}{60}
$$

Para a cultura de soja tem-se

$$
X=\frac{P}{40}
$$

Note-se que a definição dos valores de X utilizą da no ajustamento de (3) é distinta da definição dos valores de X utilizada no ajustamento de (1).

3.5.1.2. Função raiz quadrada

Como a função quadrática, a raiz quadrada também é muito utilizada em experimentos de adubação na determinação da dose mais econômica de nutriente.

Especificamente o modelo raiz quadrada a ser uti lizado, apresenta a seguinte forma:

$$
Y=\alpha+\beta_{1} X+\beta_{2} \sqrt{X}+E
$$

onde: $Y=$ produção de milho (soja) em kg/ha

$$
\alpha=\text { termo constante }
$$


$\mathrm{X}=$ doses de nitrogênio, $\mathrm{P}_{2} \mathrm{O}_{5}$ ou $\mathrm{K}_{2} \mathrm{O}$ por hectare, como es pecificado no final da seção anterior para a função

$\beta_{1}$ e $\beta_{2}=$ coeficientes de regressão

$\mathrm{E}:=$ erros.

Espera-se encontrar a estimativa do coeficiente do termo raiz quadrada positivo, que é a condição para que a função apresente rendimentos marginais decrescentes.

\subsubsection{Função de Mitscherlich}

A função de Mitscherlich não apresenta ponto de máximo. Assim, não é apropriada para representar resposta a fertilizantes, em experimentos de campo, quando as magnitudes de insumos são bastante grandes a ponto de causar um declínio na produção.

Segundo PIMENTEL GOMES (1982), para maior facilidade do uso da lei de Mitscherlich devemos, tal como no caso dos polinômios ortogonais, adotar níveis de fertilização igual mente espaçados. A teoria e a prática demonstram que a lei de Mitscherlich tem aplicação satisfatōria e ūtil sempre que temos ensaios de grande precisão ou grupos de experimentos numerosos. A aplicação se torna desaconselhável no caso de experi mentos de precisão escassa ou quando a planta reage muito mal ao nutriente em estudo.

Deve-se ressaltar que esta consideração é válida para qualquer modelo. 
A função de Mitscherlich pode expressar-se da se

guinte forma:

$$
Y=\alpha\left[1-10^{-\gamma(x+\delta)]}+E\right.
$$

onde: $\mathrm{Y}=$ produção de milho $(\operatorname{soja})$ em $\mathrm{kg} / \mathrm{ha}$

$\mathrm{X}=$ quantidade de nitrogênio, $\mathrm{P}_{2} \mathrm{O}_{5}$ ou $\mathrm{K}_{2} \mathrm{O}$, em kg/ha

$\alpha=$ produção máxima teórica possível quando se aumenta indefinidamente a dose de um nutriente

$\gamma=$ coeficiente de eficácia

$\delta=$ teor do nutriente contido no solo em forma assimilável pelas plantas

$E=$ erros.

\subsubsection{Funções estimadas}

Considerando a, b, c, d as estimativas de minimos quadrados dos parâmetros $\alpha, \beta, \gamma$ e $\delta$ respectivamente, e se $\widehat{Y}$ é a produtividade estimada, teremos então as estimativas dos modelos adotados:

$$
\begin{aligned}
\hat{Y}= & a+b_{1} x_{1}+b_{2} x_{2}+b_{3} x_{3}+b_{11} x_{1}^{2}+b_{22} x_{2}^{2}+b_{33} x_{3}^{2}+ \\
& +b_{12} x_{1} x_{2}+b_{13} x_{1} x_{3}+b_{23} x_{2} x_{3} \\
\hat{Y}= & a+b_{1} x_{1}+b_{2} x_{2}+b_{11} x_{1}^{2}+b_{22} x_{2}^{2}+b_{12} x_{1} x_{2} \\
\hat{Y}= & a+b_{1} X+b_{11} x^{2} \\
\hat{Y}= & a+b_{1} X+b_{2} \sqrt{X} \\
\hat{Y}= & a[1-10-c(X+d)]
\end{aligned}
$$


Para os modelos (6) a (9) as estimativas de seus parâmetros podem ser obtidas pelo método de mínimos quadrados ordinārios.

Colocando o modelo (5) na forma:

$$
Y=\alpha+\beta \rho^{X}+E
$$

$\operatorname{Com} \alpha>0 ; \beta<0$ e $|\rho|<1$, conhecida como função de Spillman, podemos determinar as estimativas de mínimos quadrados de $\alpha$, B e p pelo método de Gauss-Newton.

Sendo a, b, r as estimativas dos parâmetros $\alpha, \beta$ e $\rho$, respectivamente, e $\hat{Y}$ a produtividade estimada, temos então a função de Spillman estimada: $\hat{Y}=a+b r^{x}$.

As condições impostas aos valores dos parâmetros, garantem que todos os modelos de função de produção apresentem um intervalo em que o produto físico marginal (PFMg) é decrescente e o produto físico médio (PFMe) é decrescente maior que o PFMg.

Ao ajustar as equações (8), (9) e (10), as estimativas dos desvios padrões das estimativas dos parâmetros foram obtidas utilizando o quadrado médio do resíduo da anālise de variância completa (na qual se considerou tanto o efeito de tratamento como o efeito de blocos) como estimativa da variância residual ou variância do erro. 


\subsubsection{Variáveis Binárias}

Variāveis binárias (Dummy variables) são utilizą das para representar variáveis qualitativas ou mudanças sūbitas no processo em anālise. Em funções de produção, as variāveis binārias são usadas para representar alterações tanto no intercepto como na declividade da função. Em nosso estudo usa remos estas variáveis somente para representar alterações no intercepto da função, devidas aos efeitos de blocos.

Assim, para o experimento de milho, temos 6 blo$\cos \left(3\right.$ em cada um dos ensaios $3^{3}$ ). Esses blocos foram distinguidos através de 5 variáveis binárias, como mostra a tabela 3.5 .

Tabela 3.5 - Valores das variāyeis binárias usadas para distin guir os 6 blocos no experimento de milho.

Variāveis binärias

B 1ocos

$$
\mathrm{Z}_{1}
$$

$\mathrm{Z}_{2}$

$\mathrm{Z}_{3}$

$\mathrm{Z}_{4}$

$z_{5}$

1

0

0

0

0

0

Ensaio 12

3

1

0

0

0

0

(1)

1

0

1

0

0

0

$1-0$

0

1

0

0

Ensaio 22

0

0

0

1

0

3

0

0

0

1 
No caso do experimento de soja usamos variáveis binárias para distinguir as diferenças entre os 5 blocos anali sados, como mostra a tabela 3.6 .

Tabela 3.6 - Valores das variáveis binárias usadas para distin guir os 5 blocos no experimento de soja.

\begin{tabular}{ccccc}
\hline & \multicolumn{4}{c}{ Variáveis binārias } \\
\cline { 2 - 5 } Blocos & $\mathrm{z}_{1}$ & $\mathrm{z}_{2}$ & $\mathrm{z}_{3}$ & $\mathrm{z}_{4}$ \\
\hline 1 & 0 & 0 & 0 & 0 \\
2 & 1 & 0 & 0 & 0 \\
3 & 0 & 1 & 0 & 0 \\
4 & 0 & 0 & 1 & 0 \\
5 & 0 & 0 & 0 & 1 \\
\hline
\end{tabular}

3.6. Determinação do Nivel Economicamente ótimo de Insumos

o procedimento usual é a maximização da função

lucro $(\pi)$, a qual pode ser definida pela equação:

$$
\pi=P_{Y} Y-\sum P_{X i} X i-C
$$

onde: $\pi=$ renda líquida

$$
\begin{aligned}
& \mathrm{C}=\text { custos fixos } \\
& \mathrm{Y}=\text { quantidade do produto (milho ou soja) }
\end{aligned}
$$


$\mathrm{P}_{\mathrm{Xi}}=$ preço unitário dos insumos, incluindo custos variāveis de aplicação dos mesmos (ver tabela 3.7 ).

$\mathrm{P}_{\mathrm{Y}}=$ preço unitário do produto (milho ou soja) pago ao agricultor

$X_{i}=$ quantidades dos fatores.

Informações sobre os preços foram obtidas através de consuta das "Solicitações de Empenho" do campus de Ilha Solteira - UNESP, para os anos de 1981/82.

Tabela 3.7 - Estimativa de Custo Variável de Aplicação de Insu mos por Hectare, Ano Agrícola 1981/82.

\begin{tabular}{lccc}
\hline \multicolumn{1}{c}{ Insumos } & Quantidade & $\begin{array}{c}\text { Preço unitārio } \\
(\operatorname{Cr} \$)\end{array}$ & $\begin{array}{c}\text { Valor total } \\
(\text { Cr } \$)\end{array}$ \\
\hline Nitrogênio $(\mathrm{N})$ & $60 \mathrm{~kg}$ & 165,00 & $9.900,00$ \\
Fósforo $\left(\mathrm{P}_{2} \mathrm{O}_{5}\right)$ & $50 \mathrm{~kg}$ & 170,00 & $8.500,00$ \\
Potássio $\left(\mathrm{K}_{2} \mathrm{O}\right)$ & $40 \mathrm{~kg}$ & 100,00 & $4.000,00$ \\
Óleo Diese1. & 3,01 & 50,00 & 150,00 \\
Mão-de-obra & $1,00 \mathrm{~h}$ & 81,35 & 162,00 \\
\hline
\end{tabular}

Custo total da aplicação de:

- Nitrogênio Cr\$170,00 por kg

- Fósforo Cr\$176,00 por kg

- Potássio Cr\$103,00 por kg

Para o cálculo do custo de espaçamento foi consi derado o preço da semente de soja Santa Rosa: Cr\$2.080,00/sc de $50 \mathrm{~kg}$. 
No que se refere aos produtos, os preços básicos considerados para o cálculo da dose ótima econômica foram de $\operatorname{Cr} \$ 2.000,00 / \mathrm{sc}$ de $60 \mathrm{~kg}$ de soja e $\operatorname{Cr} \$ 1.020,00 / \mathrm{sc}$ de $60 \mathrm{~kg}$ de milho (preços médios recebidos em julho de 1982).

Ressalte-se, entretanto, que neste trabalho determinaremos o nível economicamente ótimo do fator. para vārias relações de preços, dentro de certo intervalo, delimitado com base nos preços acima.

A condição necessāria para que a receita líquida seja máxima, é que a derivada de $\pi$ com relação a $x_{i}$ seja igual a zero.

$$
\begin{aligned}
& \frac{d \pi}{d X_{i}}=P_{Y} \cdot \frac{d Y}{d_{X_{i}}}-{ }^{P_{X}}=0 \\
& \frac{d Y}{d X_{i}}=\frac{{ }^{P_{X}}}{P_{Y}}
\end{aligned}
$$

Para determinar as quantidades de nutrientes que maximizam os lucros, igualam-se as produtividades físicas marginais de cada nutriente com a relação entre o preço do fator e o preço do produto. Entretanto, lembrando VIEIRA (1980), quan do os custos de colheita por unidade de produto forem variáveis, deve-se subtraí-los do preço do produto pago ao agricultor. 
3.7. Determinação do Espaçamento ótimo para a Soja

$$
\text { Sabe-se que em um hectare tem-se } 10^{4} \mathrm{~m}^{2} \text { ou } 10^{8} \mathrm{~cm}^{2} \text {. }
$$

Se E é o espaçamento entre linhas em $\mathrm{cm}$, o número de cm de linha em um hectare é dado por $\frac{10^{8}}{E}$. Conclui-se que o número de m de linha em um hectare é igual a $\frac{106}{E}$. Sendo $\phi$ o custo com semente por metro de Iinha, o custo/ha é dado por $\frac{10^{6} \phi}{E}$. Sendo C o custo dos fatores fixos, a receita líquida será dada por

$$
\pi=Y \cdot P_{Y}-\left(\theta \frac{1}{E}+C\right)
$$

onde $\theta$ é um coeficiente de proporcionalidade. Segue-se que

$$
\pi=Y \cdot P_{Y}-\frac{\theta}{E}-C
$$

Como $\frac{10^{6} \phi}{E} \bar{e}$ o custo com semente/ha verifica-se que

$$
\theta=10^{6} \phi
$$

A condição de primeira ordem para receita líquida máxima é que a derivada em relação a E seja nula, isto é, quando

ou

$$
\begin{aligned}
& \frac{d Y}{d E} \cdot P_{Y}+\frac{\theta}{E^{2}}=0 \\
& \frac{d Y}{d E}=-\frac{\theta}{E^{2} \cdot P_{Y}}
\end{aligned}
$$


Lembrando que $x_{2}=\frac{E-35}{5}$, temos.

$$
E=35+5 X_{2}
$$

Como

$$
\frac{d Y}{d E}=\frac{d Y}{d X_{2}} \cdot \frac{d_{2}}{d E}
$$

temos :

$$
\frac{d Y}{d E}=\frac{d Y}{d \dot{X}_{2}} \cdot \frac{1}{5}
$$

Substituindo (11), (13) e (14) em (12)

ou

$$
\begin{aligned}
& \frac{d Y}{d X_{2}} \cdot \frac{1}{5}=\frac{-10^{6} \phi}{P_{Y}\left(35+5 X_{2}\right)^{2}} \\
& \frac{d Y}{d X_{2}}=\frac{-5 \cdot 10^{6} \cdot \phi}{P_{Y}\left(35+5 X_{2}\right)^{2}}
\end{aligned}
$$

Obtidas as doses ōtimas econômicas dos nutrientes e espaçamento, serão determinados os seus respectivos intervalos de confiança através de dois métodos. Um método se ba seia na Variância Assintótica da estimativa da dose econômica e o outro é dado pelo Teorema de Fieller². Segundo HoFFMANN e VIEIRA (1976), o método baseado no Teorema de Fieller é o mais apropriado.

\footnotetext{
${ }^{2}$ Ver Hoffmann e Vieira (1977), p. 318.
} 
4. RESULTADOS E DISCUSSÃO

4.1. Anāilise dos Resultados de Produção

os rendimentos médios de milho e soja obtidos nos dois experimentos são apresentados nas tabelas 4.1 e 4.2 .

No ensaio de milho o maior rendimento médio obti do foi de $4.030 \mathrm{~kg} / \mathrm{ha}$, quando os níveis de $\mathrm{N}, \mathrm{P}_{2} \mathrm{O}_{5}$ e $\mathrm{K}_{2} \mathrm{O}$ foram de 80,170 e $80 \mathrm{~kg} / \mathrm{ha}$, respectivamente. Este rendimento é relativamente elevado, maior do que o rendimento médio no estado de São Paulo (2.400 kg/ha, média dos ültimos 4 anos; ver IEA, $1982 / 83)$

Nos 27 tratamentos dos dois ensaios, os resultados médios de produção variam de $1907 \mathrm{~kg} / \mathrm{ha}$ (menores níveis dos nutrientes estudados) a $4.030 \mathrm{~kg} / \mathrm{ha}$ (tratamento de maior produ ção), observando-se um acrēscimo superior a 50\%. Convém considerar que isto não significa necessariamente que se deva atin gir estes níveis de nutrientes para obtenção de uma produção 
Tabela 4.1 - Resultados Obtidos para a Cultura de Milho com Hmd 7974. Ano Agrícola 1981/82.

Combinação de níveis de $\mathrm{N}, \mathrm{P}_{2} \mathrm{O}_{5}$ e $\mathrm{K}_{2} \mathrm{O}$, em kg/ha
Produção de grãos em $\mathrm{kg} / \mathrm{ha}$

Ensaio 1 Ensaio 2

1955

1565

2358

2358

2488

3250

2660

2710

2065

2458

2360

3154

2565

2810

3658

2850

4450

3000

2208

$140-30-20$

$140-30-80$

$140-30-140$

$140-100-20$

$140-100-80$

$140-100-140$

$140-170-20$

$140-170-80$

$140-170-140$
Média dos tratamentos
1907,5
1726,5
2626,5
2329,0
2619,0
3005,0
2960,0
2680,0
2532,5
2989,0
2105,0
3027,0
2332,5
2839,0
3479,0
2765,0
4030,0
3125,0
2684,0
3254,0
2414,0
2931,0
2325,0
2075,0
2585,0
3134,0
3216,0 


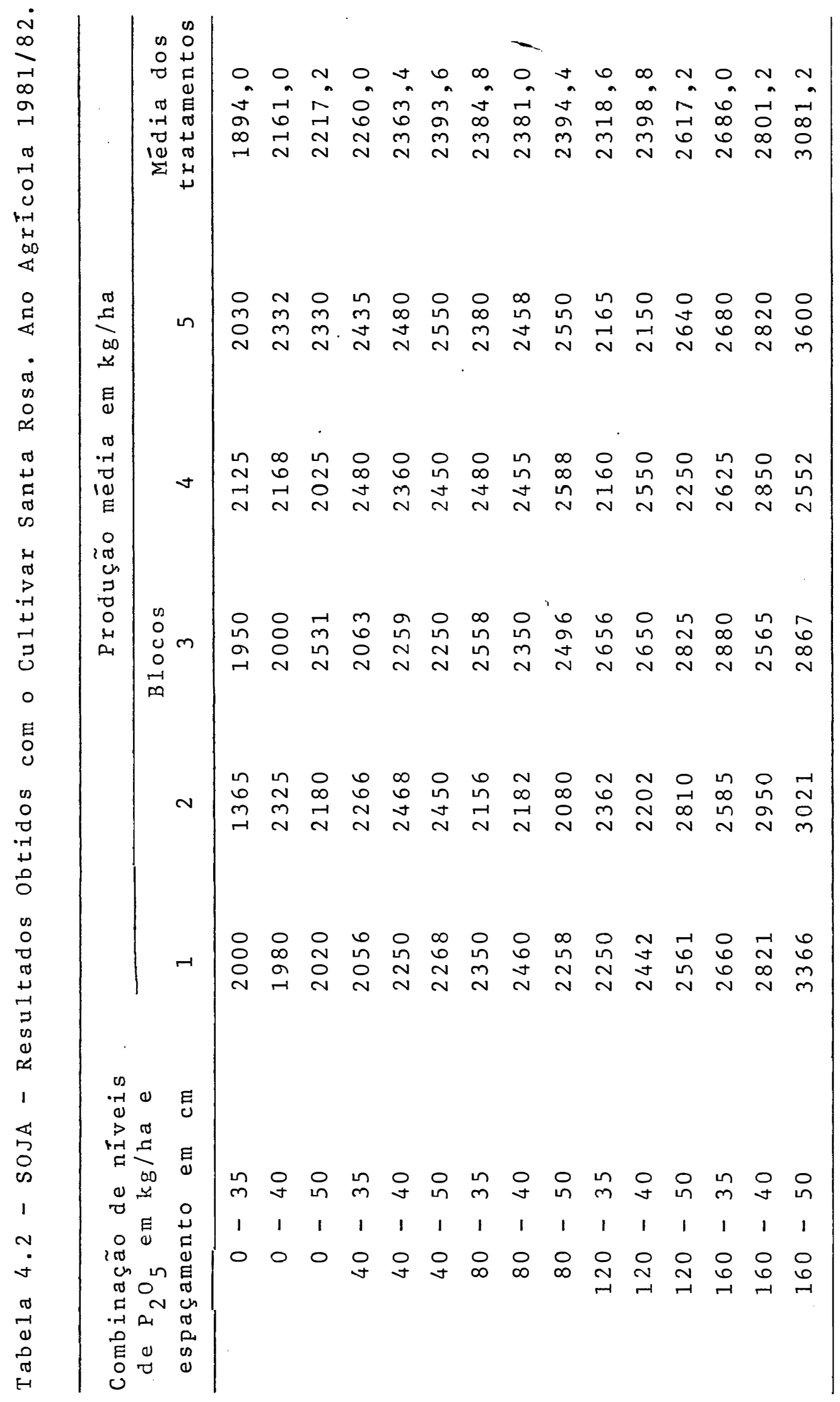


tão elevada, uma vez que o nível ótimo de produção em relação a um fator variāvel dependerā da PFMg desse fator, do seu custo, do preço do produto e do próprio nível de utilização dos demais fatores.

Tomando-se agora os dados de rendimento - físico médio para a soja, observamos que no geral a produtividade média da soja cresce quando se aumenta a quantidade de fósforo, sendo este aumento mais expressivo quando se utiliza a maior dose de fósforo. Isto mostra que a dose de $160 \mathrm{~kg} / \mathrm{ha}$ provavel mente ainda se encontra no segundo estágio da função de produção. O maior rendimento médio obtido foi de $3.081 \mathrm{~kg} / \mathrm{ha}$, quan do o nível de $\mathrm{P}_{2} \mathrm{O}_{5}$ era de $160 \mathrm{~kg} / \mathrm{ha}$ e o espaçamento de $50 \mathrm{~cm}$.

Observa-se que, em relação ao nível zero de aplí cação de fósforo, foram obtidos aumentos médios máximos de $1.187 \mathrm{~kg} / \mathrm{ha}$ de soja.

4.2. Anālise de Regressão

4.2.1. Estimativa dos parâmetros e doses econômicas pá ra a cultura de milho

Os resultados estatísticos das equações de regressão quadrātica, raiz quadrada e Mitscherlich, ajustadas pa ra a cultura de milho, são apresentados nas tabelas 4.3 a 4.10.

As estimativas das superfícies de produção para os modelos estudados apresentaram resultado significativo do 
teste $F$ para o coeficiente de determinação múltipla $\left(R^{2}\right)$, como se pode ver nas tabelas 4.3 e 4.4 .

0 coeficiente de determinação múltipla $\left(R^{2}\right)$ do ensaio 1 foi o que apresentou maior valor $(0,71)$, indicando um melhor ajustamento. $\quad 0 \mathrm{R}^{2}$ indica em que proporção as variações na produção de milho podem ser explicadas por tal ajustamento.

Verifica-se pelas tabelas 4.3 e 4.4 que as estimativas dos coeficientes de regressão; associados aos nutrientes $N, P$ e K e interações, foram em sua maioria não-significa tivos aos níveis de significância considerados ( $1 \%, 5 \%$ e $10 \%$ ).

Somente no caso do ensaio 2 , os termos lineares e quadráticos apresentaram o sinal esperado, ou seja, positivo e negativo, respectivamente, para os três nutrientes. 0 sinal negativo do termo quadrático indica que a lei dos rendimentos marginais decrescentes se fez presente. No caso do ensaio 1 e para o conjunto dos dois ensaios, a superficie ajustada apresenta ponto de sela.

0 coeficiente de correlação entre $x_{1}$ e $x_{1}^{2}$, entre $x_{2}$ e $x_{2}^{2}$ e entre $x_{3}$ e $x_{3}^{2}$ é igual a 0,9897 . Verifica-se, também, que os coeficientes de correlação entre os termos lineares ( $N$, $\mathrm{P}$ e K) e as interações (NP, NK e PK) assumem valores de 0,6723 a 0,6793 .

A existência de variäveis altamente correlacionadas eviden cia a presença de multicolinearidade na matriz de variáveis independentes ${ }^{3}$.

${ }^{3} \bar{E}$ interessante assinalar que a correlação entre os termos lineares e os termos quadrāticos poderia ser eliminada redefinindo as variāveis $x_{1}, x_{2}$ e $\mathrm{X}_{3}$ de maneira que seus valores fossem $-1,0 \mathrm{e}+1$. 
Lembrando WRIGHT (1973), uma desvantagem da função quadrätica é relativa à possibilidade de introduzir alta correlação entre os temos lineares e quadráticos e os termos de interação com outras variāveis.

Através da anālise das tabelas 4.5 a 4.10 , pode-se notar inicialmente que os resultados dos testes estatísti cos foram em sua maioria não-significativos.

Nos três modelos de regressão (quadrātico, raiz quadrada e Mitscherlich), obteve-se resultado não-significati vo do teste $F$ para $R^{2}$.

Dentre os três nutrientes estudados, no caso do nitrogênio os coeficientes apresentaram em todos os modelos estudados, o sinal esperado para determinação da dose ótima econômica.

Nas tabelas 4.11 e 4.14 são dadas, para os três modelos considerados, as estimativas das doses econômicas de nitrogênio, fósforo e potássio, os intervalos de confiança com base na Variância Assintótica e no Teorema de Fieller e as estimativas da produção ótima de milho para vārias relações de preços.

Com respeito ao valor da relação entre o preço do kg do nutriente e o preço do kg de milho, procuramos consi derar um intervalo que englobasse as situações prevalecentes nos últimos anos. 
Analisando as tabelas 4.11 a 4.14 , notamos que a amplitude dos intervalos de confiança (com base na Variância Assintótica e no Teorema de Fieller) para as doses econômicas de $N, P$ e K é bem menor para o modelo raiz quadrada. Isso mos t'ra que o modelo raiz quadrada permitiu obter estimativas de dose econômica mais precisas.

Pela tabela 4.11, observamos que os resultados obtidos para as doses econômicas de nitrogênio são mais concor dantes entre os modelos raiz quadrada e Mitscherlich do que pa ra o modelo quadrático. Os intervalos de confiança para os mo delos quadrāticos e Mitscherlich são muito amplos, não permitindo indicar dose ótima econômica confiāvel. Para o modelo raiz quadrada, os limites superiores dos dois intervalos de con fiança são mais ou menos semelhantes, mas ainda assim de uma amplitude demasiadamente grande para que se possa indicar com segurança uma dose ótima econômica.

Quando se consideram os intervalos de confiança baseados na Variância Assintótica e no Teorema de Fieller, para a dose econômica de $\mathrm{N}$ no ensaio 2 , considerando o modelo raiz quadrada (tabela 4.12), os resultados são bem semelhantes e de uma amplitude relativamente pequena, podendo-se mesmo indicar, para esse caso, $35 \mathrm{~kg} / \mathrm{ha}$ como dose ótima econômica de nitrogênio.

As doses economicamente ótimas de fósforo obtidas no ensaio 2 , para os 3 modelos estudados, não são simila- 
res e os intervalos de confiança são de uma grande amplitude. Quando se consideram os resultados obtidos com os modelos quadráticos e Mitscherlich, verifica-se a existência de "doses eco nômicas" negativas. Tal resultado é absurdo do ponto de vista do agricultor e a recomendação, nesse caso, é não adubar.

Para o potássio também não se pode indicar uma do se ōtima econômica confiāvel. Os intervalos de confiança são bem discrepantes e muito amplos.

Comparando os intervalos de confiança baseados na Variância Assintótica e no Teorema de Fieller nas tabelas 4.11 a 4.14, verificamos que na maioria dos casos os intervalos de confiança são bastante discrepantes. Em apenas um caso (tabela 4.12) a amplitude dos dois intervalos de confiança são bem similares. Lembrando HOFFMANN e VIEIRA (1976, p.55), quan do houver discrepância entre os dois intervalos de confiança devemos adotar o intervalo de confiança baseado no Teorema de Fieller. Este teorema indica corretamente a indeterminação de um cociente quando o denominador da fração é estatisticamente diferente de zero. Nesse caso o intervalo de confiança será constituído por todo o campo real $(-\infty$ a $+\infty)$ ou será constituído por dois sub-intervalos. Nesse $\bar{l}$ ltimo caso, apenas um dos sub-intervalos irá conter o valor de $X$ que satisfaz as condições para renda líquida máxima e apenas esse sub-intervalo é apresentado na tabela. Deve-se ressaltar que a esse sub-inter valo não corresponde, evidentemente, o nível de confiança ado- 
tado de $90 . \%^{4}$.

$\bar{E}$ certo que as Variâncias Assintóticas também dão uma boa aproximação da variância de $\mathrm{X}$ quando o tamanho da amos tra é.suficientemente grande. Porém è difícil estabelecer o tamanho de uma amostra para que ela possa ser considerada "suficientemente grande".

Reconsiderando o Teorema de Fieller, um ponto que deve ser ressaltado é que seu limite inferior nunca cresce quan do se aumenta a relação de preços comportando-se de acordo com a lei de rendimentos marginais decrescentes. Por outro lado, HOFFMANN e, VIEIRA (1976, p.56) constataram casos em que o 1 imi te inferior do intervalo de confiança, baseado na Variância As sintótica, cresceu quando se aumentou a relação de preços. Em nosso caso isto foi verificado para a determinação da dose eco nômica de nitrogênio para o ensaiol (tabela 4.11) e de fósforo, para o ensaio 2 (tabela 4.13).

Podemos observar também que, para determinação da dose econômica de fósforo para o ensaio 2 no modelo quadrático o limite superior do intervalo de confiança baseado na Variância Assintótica, cresceu à medida que se aumentọu a relação de preços. Por exemplo, quando a relação de preços cresce de 8,0 para 9,0, o limite superior do intervalo de confiança da dose econômica de fósforo aumenta de 539,6 a 634,9. Entretanto, o

4 Esse problema é discutido em PIMENTEL GOMES e GOMES (1979). 
Tabela 4.3 - Resultados Estatísticos das Equações de Regressão Quadrática Ajustadas para a Cultura de Milho - 54 Observações. Ano Agrícola 1981/82.

\begin{tabular}{|c|c|c|c|}
\hline Coeficientes & $\begin{array}{c}\text { Estimativas dos } \\
\text { coeficientes }\end{array}$ & $\begin{array}{l}\text { Desvio } \\
\text { padrão }\end{array}$ & Teste $t$ \\
\hline$\cdot \mathrm{a}$ & $-187,0$ & $1006,2:$ & $-0,18^{\mathrm{NS}}$ \\
\hline$c_{1}$ & $-124,6$ & 207,5 & $-0,60^{\mathrm{NS}}$ \\
\hline$c_{2}$ & 130,8 & 207,5 & $-0,63^{\mathrm{NS}}$ \\
\hline$c_{3}$ & 106,8 & 207,5 & $-0,51^{\mathrm{NS}}$ \\
\hline$c_{4}$ & 647,2 & 207,5 & $3,11 * * *$ \\
\hline$c_{5}$ & 478,2 & 207,5 & $2,30 * *$ \\
\hline $\mathrm{b}_{1}$ & 1990,8 & 573,2 & $3,47 * * *$ \\
\hline $\mathrm{b}_{2}$ & 10,8 & 573,2 & $0,01^{\mathrm{NS}}$ \\
\hline $\mathrm{b}_{3}$ & 457,2 & 573,2 & $0,79^{\mathrm{NS}}$ \\
\hline $\mathrm{b}_{11}$ & $-352,3$ & 127,1 & $-2,77 \div * *$ \\
\hline $\mathrm{b}_{22}$ & 107,1 & 127,1 & $0,84^{\mathrm{NS}}$ \\
\hline$b_{33}$ & $-28,5$ & 127,1 & $-0,22^{N S}$ \\
\hline$b_{12}$ & $-107,7$ & 89,8 & $-1,19^{\mathrm{NS}}$ \\
\hline $\mathrm{b}_{13}$ & $-121,8$ & 89,8 & $-1,35^{\mathrm{NS}}$ \\
\hline$b_{23}$ & 6,3 & 89,8 & $0,07^{\mathrm{NS}}$ \\
\hline
\end{tabular}

Coeficiente de determinação mültipla $\left(\mathrm{R}^{2}\right)=0,56$

Teste $F=3,65 * * *$

Coeficiente de Variação (CV) $=16,12$

* indica significância ao nível de 0,10

$* *$ indica significância ao nível de 0,05

$* * *$ indica significância ao nível de 0,01 


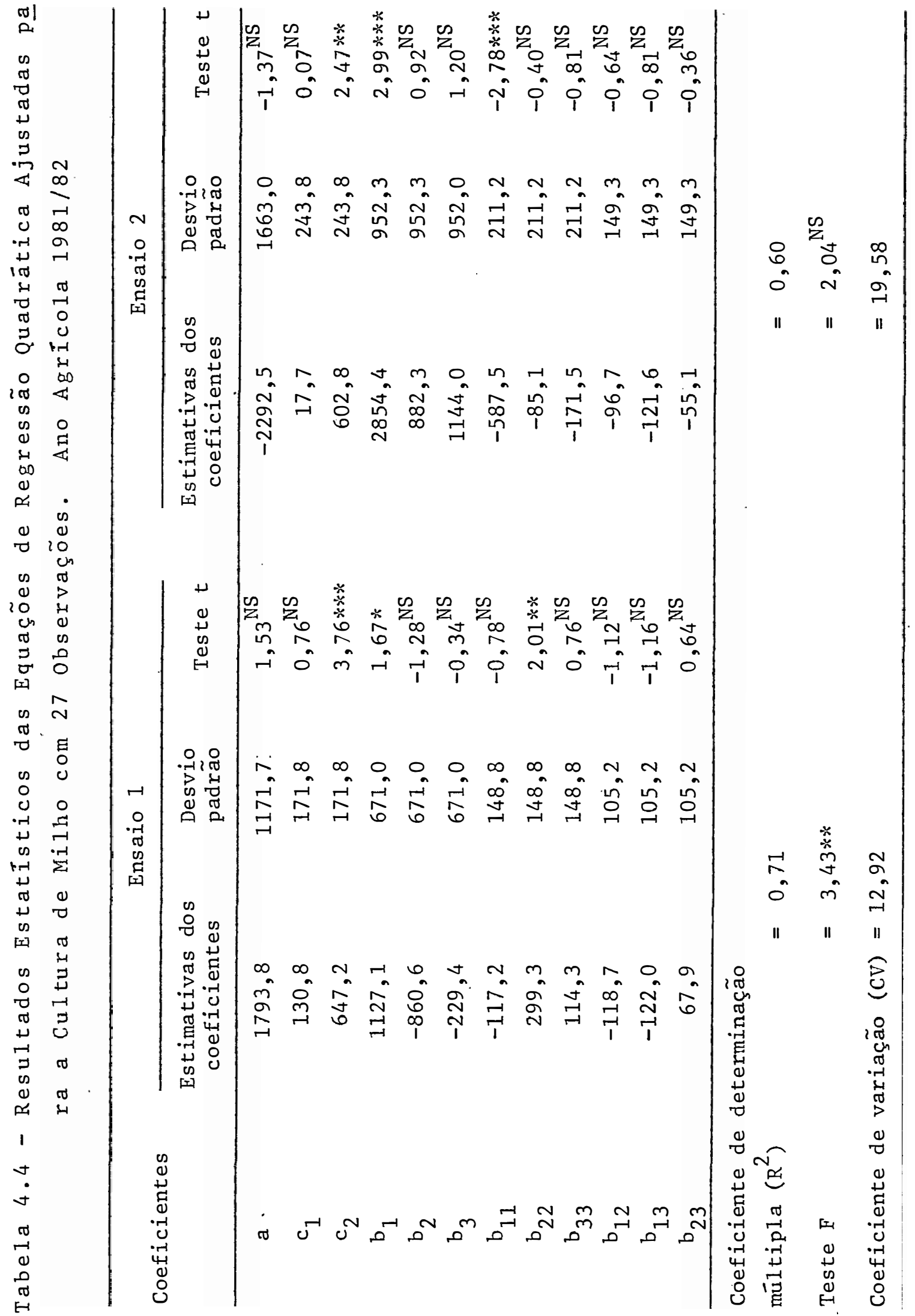


Tabela 4.5 - Resultados Estatísticos das Equações de Regressão Quadrática Ajustadas para a Cultura do Milho com 27 Observações do Ensaio 1. Ano Agrícola 1981/82.

\begin{tabular}{cccc}
\hline Coeficientes & $\begin{array}{c}\text { Estimativas dos } \\
\text { coeficientes }\end{array}$ & $\begin{array}{l}\text { Desvio } \\
\text { padrão }\end{array}$ & Teste T \\
\hline Nitrogênio & & \\
\hline $\mathrm{a}$ & 2603,8 & 121,5 & $21,43 * * *$ \\
$\mathrm{~b}_{1}$ & 410,9 & 309,7 & $1,32^{*}$ \\
$\mathrm{~b}_{11}$ & $-117,2$ & 148,8 & $-0,78^{\text {NS }}$ \\
\hline
\end{tabular}

Coeficiente de determinação $\left(R^{2}\right)=0,09$

Teste $F=1,20^{\mathrm{NS}}$

\section{Fósforo}

$\begin{array}{lrrr}\mathrm{a} & 2683,8 & 121,5 & 22,08 * * * \\ \mathrm{~b}_{1} & -363,4 & 309,7 & -1,17^{\mathrm{NS}} \\ \mathrm{b}_{11} & 299,3 & 148,8 & 2,01 * *\end{array}$

Coeficiente de determinação $\left(R^{2}\right)=0,21$

Teste $F=3,35^{\mathrm{NS}}$

\section{Potássio}

$\begin{array}{lrrr}\mathrm{a} & 2737,7 & 121,5 & 22,53 * * * \\ \mathrm{~b}_{1} & -109,0 & 309,7 & -0,35^{\mathrm{NS}} \\ \mathrm{b}_{11} & 114,3 & 148,8 & 0,76^{\mathrm{NS}}\end{array}$

Coeficiente de determinação $\left(R^{2}\right)=0,047$ Teste $F=0,60^{\mathrm{NS}}$ 
Tabela 4.6 - Resultados Estatísticos das Equações de Regressão Quadrática Ajustadas para a Cultura de Milho com 27 Observações do Ensaio 2. Ano Agrícola 1981/82.

\begin{tabular}{llll}
\hline Coeficientes & $\begin{array}{c}\text { Estimativas dos } \\
\text { coeficientes }\end{array}$ & $\begin{array}{l}\text { Desvio } \\
\text { padrão }\end{array}$ & Teste t \\
\hline
\end{tabular}

Nitrogênio

\begin{tabular}{lrrr}
\hline $\mathrm{a}$ & 2378,7 & 172,4 & $13,79 * * *$ \\
$\mathrm{~b}_{1}$ & 1242,6 & 439,6 & $2,82 * * *$ \\
$\mathrm{~b}_{11}$ & $-587,5$ & 211,2 & $-2,78 * * *$ \\
\hline
\end{tabular}

Coeficiente de determinação $\left(R^{2}\right)=0,21$

Teste $F=3,27^{\mathrm{NS}}$

Fósforo

\begin{tabular}{lrrr}
\hline $\mathrm{a}$ & 2376,0 & 172,4 & $13,77 * * *$ \\
$\mathrm{~b}_{1}$ & 408,1 & 439,6 & $0,92^{\mathrm{NS}}$ \\
$\mathrm{b}_{11}$ & $-85,1$ & 211,2 & $-0,40^{\mathrm{NS}}$ \\
\hline
\end{tabular}

Coeficiente de determinação $\left(\mathrm{R}^{2}\right)=0,10$

Teste $F=1,41^{\mathrm{NS}}$

Potàssio

\begin{tabular}{lrrr}
\hline $\mathrm{a}$ & 2480,6 & 172,4 & $14,38 * * *$ \\
$\mathrm{~b}_{1}$ & 447,3 & 439,6 & $1,01^{\mathrm{NS}}$ \\
$\mathrm{b}_{11}$ & $-171,5$ & 211,2 & $-0,81^{\mathrm{NS}}$ \\
\hline
\end{tabular}

Coeficiente de determinação $\left(R^{2}\right)=0,03$

Teste $F=0,46^{\mathrm{NS}}$ 
Tabela 4.7 - Resultados Estatísticos das Equações de Regressão Raiz Quadrada Ajustadas para a Cultura de Milho com 27 Observações do Ensaio 1. Ano Agrícola 1981/ 182.

\begin{tabular}{cccc}
\hline Coeficientes & $\begin{array}{c}\text { Estimativas dos } \\
\text { coeficientes }\end{array}$ & $\begin{array}{l}\text { Desvio } \\
\text { padrão }\end{array}$ & Teste $t$ \\
\hline Nitrogênio & & \\
\hline $\mathrm{a}$ & 2603,8 & 121,5 & $21,43^{* * *}$ \\
$\mathrm{~b}_{1}$ & $-106,7$ & 369,3 & $-0,28^{\mathrm{NS}}$ \\
$\mathrm{b}_{11}$ & 400,4 & 508,0 & $0,78^{\mathrm{NS}}$ \\
\hline
\end{tabular}

Coeficiente de determinação $\left(R^{2}\right)=0,09$

Teste $F=1,20^{\mathrm{NS}}$

Fósforo

$\begin{array}{lrrr}\mathrm{a} & 2683,8 & 121,5 & 22,08 * * * \\ \mathrm{~b}_{1} & 958,0 & 369,3 & 2,59 * * * \\ \mathrm{~b}_{11} & -1022,1 & 508,0 & -2,01 * *\end{array}$

Coeficiente de determinação $\left(\mathrm{R}^{2}\right)=0,21$

Teste $F=3,35^{\mathrm{NS}}$

Potássio

$\begin{array}{lrrr}\mathrm{a} & 2737,7 & 121,5 & 22,53 * * * \\ \mathrm{~b}_{1} & 395,8 & 369,3 & 1,07^{\mathrm{NS}} \\ \mathrm{b} & -390,5 & 508,0 & -0,76^{\mathrm{NS}}\end{array}$

Coeficiente de determinação $\left(R^{2}\right)=0,048$

Teste $F=0,60^{\mathrm{NS}}$ 
Tabela 4.8 - Resultados Estatísticos das Equações de Regressão Raiz Quadrada Ajustadas para a Cultura de Milho com 27 observações do Ensaio 2. Ano Agrícola 1981/ 182

\begin{tabular}{cccc}
\hline Coeficientes & $\begin{array}{c}\text { Estimativas dos } \\
\text { coeficientes }\end{array}$ & $\begin{array}{l}\text { Desvio } \\
\text { padrão }\end{array}$ & Teste $t$ \\
\hline Nitrogênio & \\
\hline $\mathrm{a}$ & 2378,7 & 172,4 & $13,79 * * *$ \\
$\mathrm{~b}_{1}$ & $-1350,7$ & 524,2 & $-2,57 * * *$ \\
$\mathrm{~b}_{21}$ & 2005,8 & 721,1 & $2,78 * * * *$ \\
\hline
\end{tabular}

Coeficiente de determinação $\left(R^{2}\right)=0,21$

Teste $F=3,27^{\mathrm{NS}}$

Fōstoro

$\begin{array}{lrrr}\mathrm{a} & 2376,0 & 172,4 & 13,77 * * * \\ \mathrm{~b}_{1} & 32,2 & 524,2 & 0,06^{\mathrm{NS}} \\ \mathrm{b}_{21} & 290,7 & 721,1 & 0,40^{\mathrm{NS}}\end{array}$

Coeficiente de determinação $\left(R^{2}\right)=0,10$

Teste $F=1,41^{\mathrm{NS}}$

Potássio

$\begin{array}{lrrr}\mathrm{a} & 2480,6 & 172,4 & 14,38 * * * \\ \mathrm{~b}_{1} & -309,6 & 524,2 & -0,59^{\mathrm{NS}} \\ \mathrm{b}_{21} & 585,5 & 721,1 & 0,81^{\mathrm{NS}}\end{array}$

Coeficiente de determinação $\left(R^{2}\right)=0,03$

Teste $F=0,46^{\mathrm{NS}}$ 
Tabela 4.9 - Resultados Estatísticos da Equação de Mitscherlich Ajustada para a Cultura de Milho com 27 Observações do Ensaio 1. Ano Agrícola 1981/82.

Nitrogênio

\begin{tabular}{cccc}
\hline Coeficientes & $\begin{array}{c}\text { Estimativas dos } \\
\text { coeficientes }\end{array}$ & $\begin{array}{l}\text { Desvio } \\
\text { padrão }\end{array}$ & Teste $t$ \\
\hline a & 2971,5 & 205,4 & $14,46^{*}$ ** \\
d & 78,21 & 144,45 & $0,54^{N S}$ \\
c & 0,01160 & 0,02344 & $0,49^{N S}$
\end{tabular}

Coeficiente de determinação $\left(R^{2}\right)=0,09$

Teste $F=1,20^{\mathrm{NS}}$

Tabela 4.10-Resultados Estatísticos da Equação de Mitscherlich Ajustada para a Cultura de Milho com 27 Observações do Ensaio. 2. Ano Agrícola 1981/82.

\section{Fósforo}

Coeficientes

Estimativas dos coeficientes

Desvio padrão

Teste $t$

$\begin{array}{cccc}\text { a } & 2988,4 & 864,5 & 3,45 \div * * \\ \text { d } & 148,05 & 318,52 & 0,46^{\mathrm{NS}} \\ \mathrm{c} & 0,00464 & 0,01290 & 0,36^{\mathrm{NS}}\end{array}$

Coeficiente de determinação $\left(R^{2}\right)=0,10$

Teste $F=1,41^{\mathrm{NS}}$ 


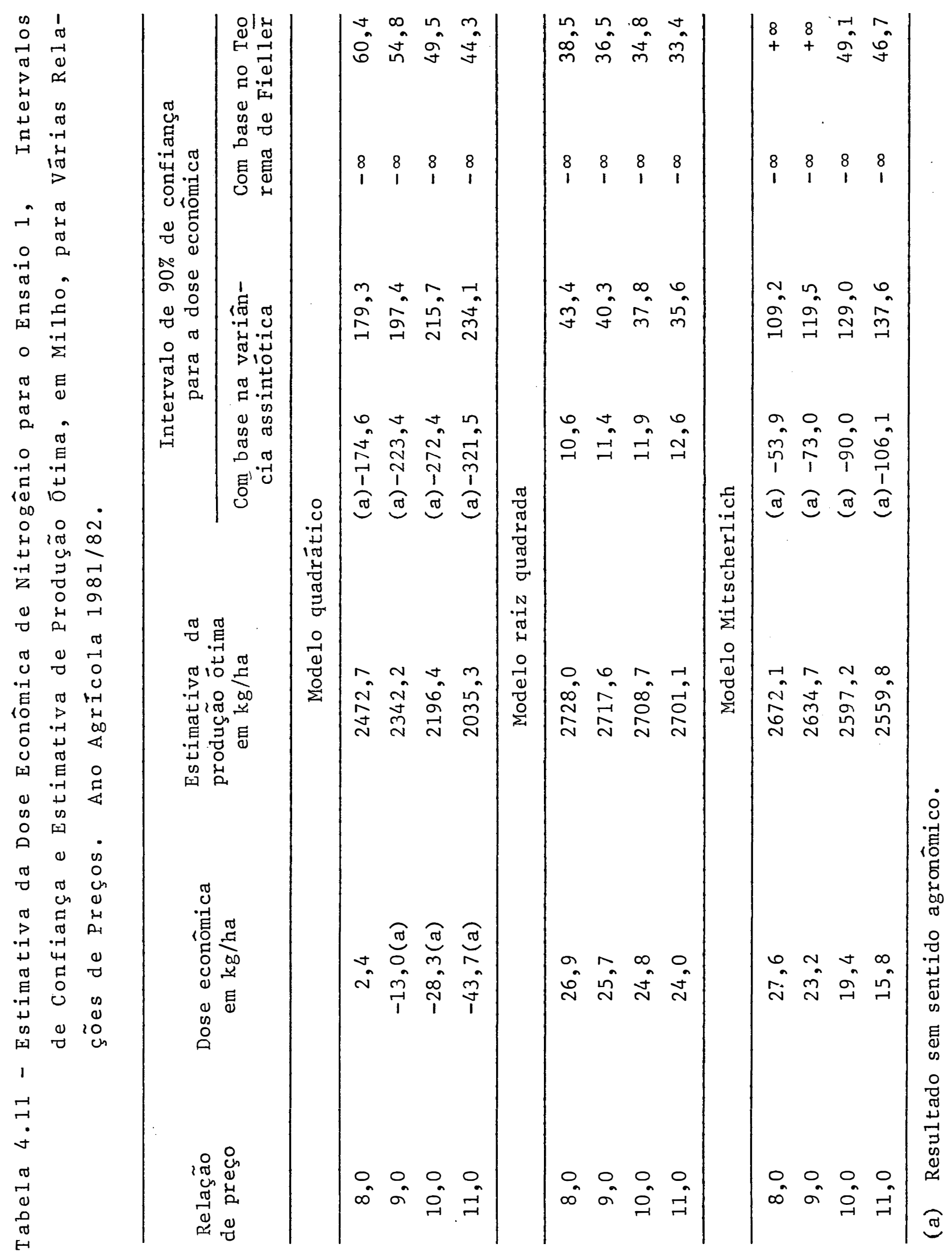




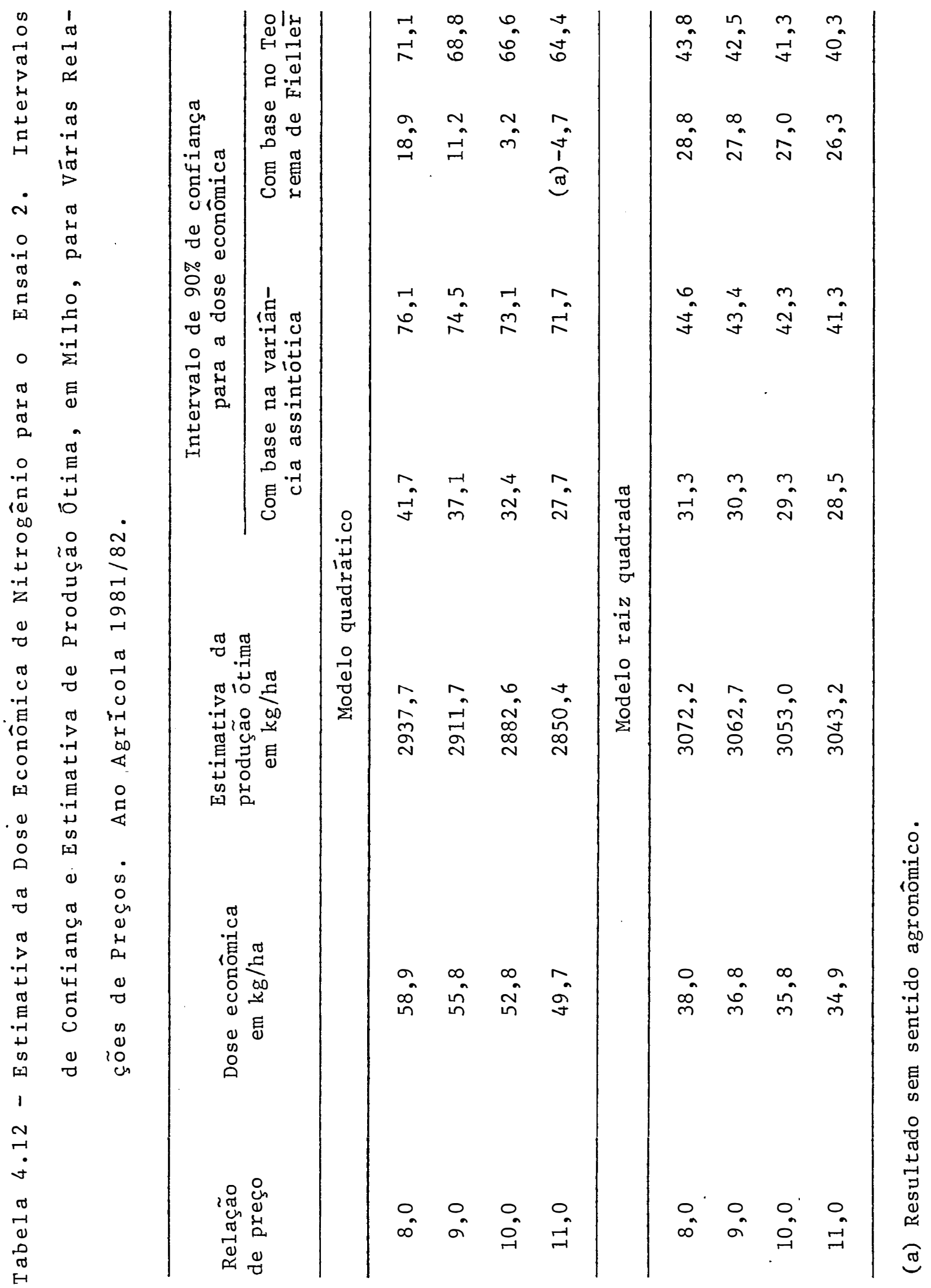




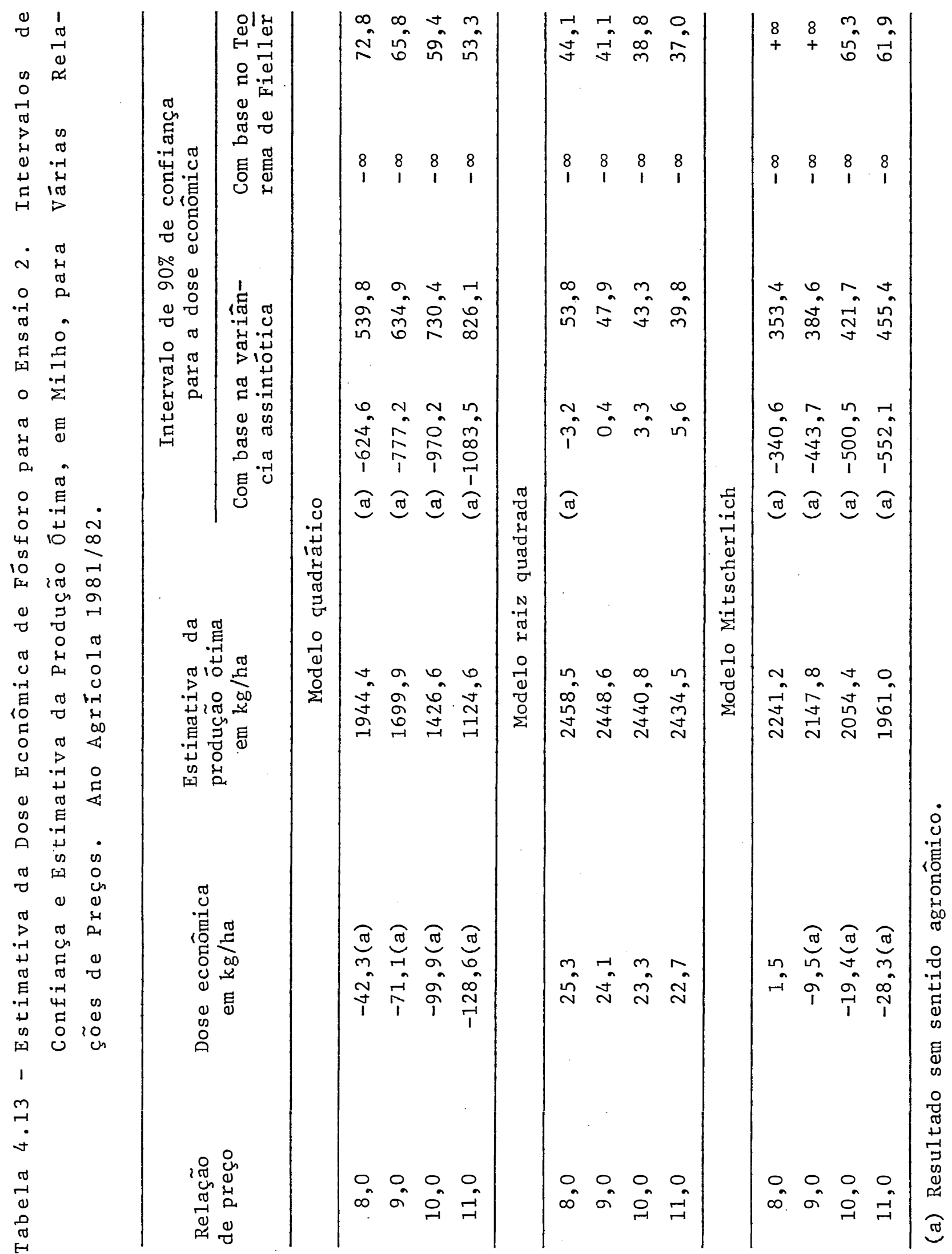




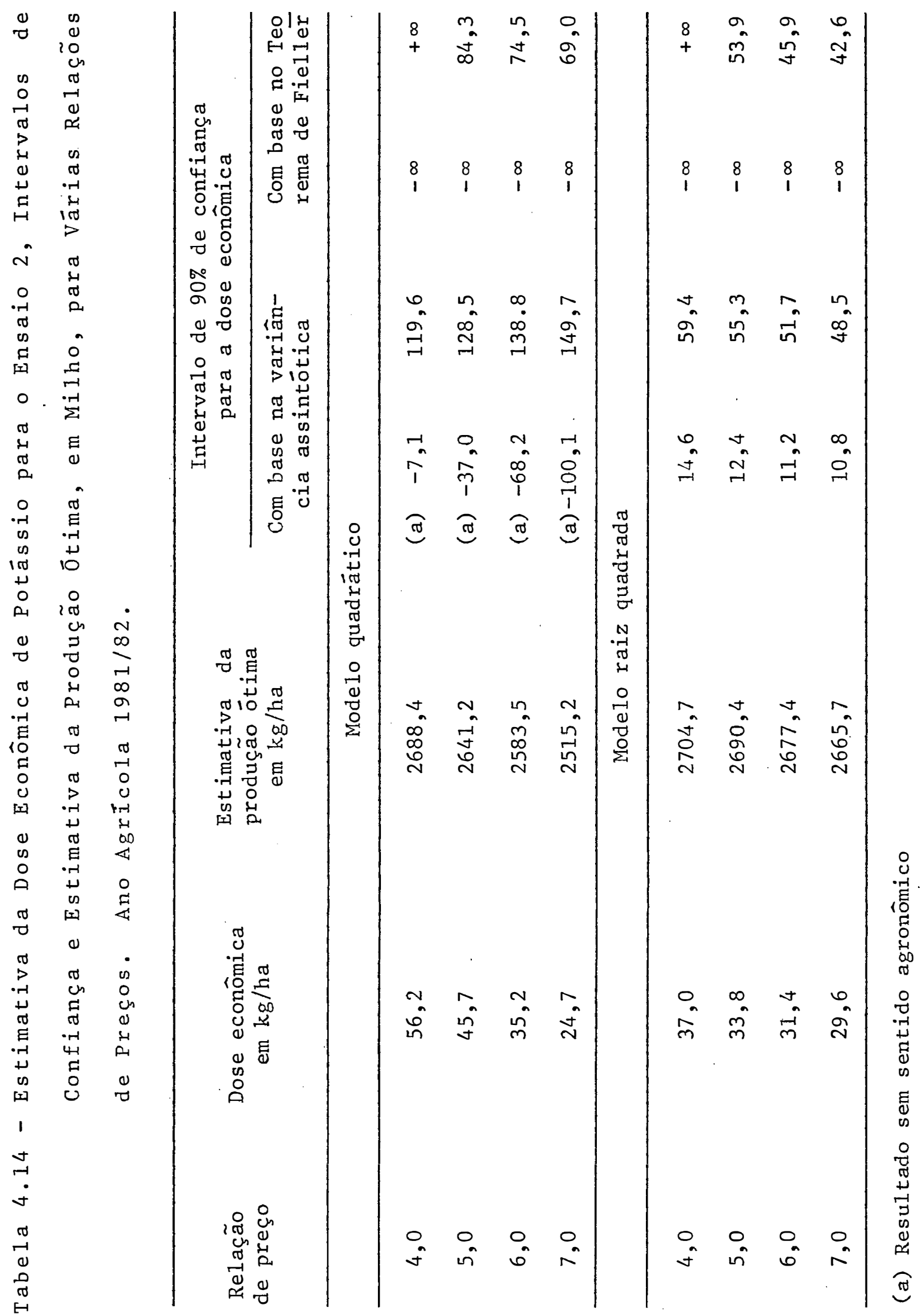


intervalo de confiança baseado no Teorema de Fieller mostra que, com a relação de preços aumentando de 8,0 para 9,0 poderíamos recomendar aplicações de doses inferiores a 72,8 e 65,8 $\mathrm{kg} / \mathrm{ha}$ de fósforo, respectivamente.

Utilizando-se os resultados obtidos com as estimativas das superfícies de produção quadrática, somente foi pos sível calcular as quantidades ótimas de nutrientes para o ensaio 2 (tabela 4.4)

Para o conjunto dos 2 ensaios (tabela 4.3) e para o ensaio 1 (tabela 4.4) as funções obtidas mostram a existência de pontos de sela, e as condiçöes de segunda ordem para lucro máximo não foram satisfeitas.

As quantidades ótimas obtidas com as relações de preços 8,0 para $\mathrm{N}$ e $\mathrm{P}_{2} \mathrm{O}_{5}$ e 4,0 para $\mathrm{K}_{2} \mathrm{O}$ foram: $68,4 \mathrm{~kg} \mathrm{de} \mathrm{N} / \mathrm{ha}$; $-32,1 \mathrm{~kg}$ de $\mathrm{P}_{2} \mathrm{O}_{5} / \mathrm{ha}$ e $77,9 \mathrm{~kg}$ de $\mathrm{K}_{2} \mathrm{O} / \mathrm{h} a$. Para as relações de preços 9,0 para $\mathrm{N}$ e $\mathrm{P}_{2} \mathrm{O}_{5}$ e 5,0 para $\mathrm{K}_{2} \mathrm{O}$ as quantidades ótimas foram: $67,9 \mathrm{~kg}$ de N/ha; $-58,0 \mathrm{~kg}$ de $\mathrm{P}_{2} \mathrm{O}_{5} / \mathrm{ha}$ e $71,2 \mathrm{~kg}$ de $\mathrm{K}_{2} 0 / \mathrm{ha}$. Da mesma forma para as relações de preços 10,0 para $\mathrm{N}$ e $\mathrm{P}_{2} \mathrm{O}_{5}$ e 6,0 para $\mathrm{K}_{2} \mathrm{O}$ as quantidades ötimas foram: $67,4 \mathrm{~kg} \mathrm{de}$ N/ha; $-83,9$ $\mathrm{kg}$ de $\mathrm{P}_{2} \mathrm{O}_{5} / \mathrm{ha}$ e $64,5 \mathrm{~kg}$ de $\mathrm{K}_{2} \mathrm{O} / \mathrm{ha}$. Finalmente, para as relações de preços 11,0 para $\mathrm{N}$ e $\mathrm{P}_{2} \mathrm{O}_{5}$ e 7,0 para $\mathrm{K}_{2} \mathrm{O}$, as quantidades ötimas foram: $66,6 \mathrm{~kg}$ de $\mathrm{N} / \mathrm{ha} ;-106,2 \mathrm{~kg}$ de $\mathrm{P}_{2} \mathrm{O}_{5} / \mathrm{ha}$ e 57,3 $\mathrm{kg} d \mathrm{e} \mathrm{K}_{2} \mathrm{O} / \mathrm{ha}$.

Comparando esses resultados com os obtidos quando se ajustou uma função de produção quadrática para cada nu- 
triente, verifica-se que, para todas as relaçöes de píços con sideradas os resultados foram bastante diferentes (ver tabelas $4.12,4.13$ e 4.14). Isto se deve aos efeitos da interação entre os nutrientes. Apesar de as interações serem estatisticamente não significativas, elas estão influindo no cálculo das doses econômicas. Deve-se ressaltar que as doses econômicas obtidas com base nas superfícies de resposta quadráticas (considerando os três nutrientes) não são, em geral, estatisticamente diferentes das doses econômicas obtidas pelo ajustamento de funções quadráticas separadamente para cada nutriente. Para que se possa afirmar, que não hā diferença estatisticamente sig nificativa, è suficiente que a dose obtida da superfície de res posta esteja dentro do intervalo de confiança para a dose econômica obtida da função quadrática ajustada separadamente para o nutriente, considerando a mesma relação de preços.

4.2.2. Estimativas dos parâmetros e doses econômicas pa ra a cultura da soja.

As estimativas dos parâmetros das equações de re gressão quadrātica, raiz quadrada e Mitscherlich, ajustadas pa ra a cultura de soja, são dadas nas tabelas 4.15 a 4.18 .

Devido ao fato de a aplicação de $160 \mathrm{~kg} / \mathrm{ha}$ de $\mathrm{P}_{2} \mathrm{O}_{5}$ apresentar resultados de produção muito alta, quando comparada com os outros tratamentos, resolveu-se ajustar funções de produção eliminando este ūltimo tratamento, isto é, incluin do apenas as 60 observações. 
Para todos os modelos estudados, obteve-se resu tados significativos do teste $F$ para o coeficiente de determinação $\left(R^{2}\right)$. O maior valor conseguido para $R^{2}$ foi 0,61 , indicando que $61 \%$ da variação total da produção de soja, por hectą re, é explicada pela regressão quadrática considerada.

As estimativas das superfícies de produção, quan do se utilizou 75 observações (tabela 4.15), apresentaram resultado não significativo para quase todos os coeficientes das variáveis. Eliminando o último tratamento no ajustamento da função, a maioria dos coeficientes das variáveis são estatistí camente significativos.

os valores dos coeficientes de correlação simples entre E e $E^{2}$ e entre $P$ e $P^{2}$ são iguais a 0,9732 e 0,9583, respectivamente. As correlações entre as interações e os termos lineares e quadráticos variaram de 0,5036 a 0,6948.

Analisando as tabelas 4.16 e 4.17 verifica-se que para 75 observações, a falta de significância dos coeficientes de regressão e o problema de "erro" de sinal, torna inviável o cálculo de dose ótima econômica, o mesmo não ocorrendo para to dos os modelos estudados quando se utilizou 60 observações.

Na tabela 4.19 são dadas, para os três modelos considerados, as estimativas das doses económicas de fósforo, intervalos de confiança, com base na Variância Assintótica e no Teorema de Fieller, e estimativas de produção ótima de soja para vārias relações de preços. 
Confirmando os resultados obtidos nos ensaios de milho, notamos que a amplitude dos intervalos de confiança, com base na Variância Assintótica e no Teorema de Fieller para a dose econômica de fósforo é bem menor quando se utiliza o mode 10 raiz quadrada. Nesse caso os dois intervalos de confiança se apresentam semelhantes e de uma amplitude relativamente pequena, podendo-se indicar como dose ótima de fósforo, para a me nor relação de preços considerada, $28 \mathrm{~kg} / \mathrm{ha}$ de $\mathrm{P}_{2} \mathrm{O}_{5}$.

Para os modelos quadrático e Mitscherlich não se pode indicar uma dose ótima econômica confiável. Os intervalos de confiança são bem discrepantes e muito amplos.

A fim de proceder ao cálculo das doses ótimas eco nômicas dos resultados obtidos com as estimativas das superfícies de produção quadrática (tabela 4.15), foram utilizadas quatro relações de preços para os fatores e o produto.

As relações de preços utilizadas foram: 3,0;4,0; 5,0 e 6,0 para o nutriente fósforo e 1,$4 ; 1,6 ; 1,8$ e 2,0 para o espaçamento. As quantidades ótimas obtidas para o fósforo foram: 54,$4 ; 37,7 ; 20,8$ e 4,0 kg/ha de $\mathrm{P}_{2} \mathrm{O}_{5}$. Comparando esses resultados com os obtidos quando se ajustou uma função de produção incluindo somente o nutriente, verifica-se que, para todas as relações de preços consideradas os resultados foram semelhantes. Isso está de acordo com VIEIRA (1980), que afirma que quando as interações são não-significantes as quantidades econômicas de nutrientes obtidas separadamente são: anālogas 
àquelas obtidas através de funções que incluem todos os nutrientes.

Os espaçamentos ótimos encontrados para a soja com as mesmas relações de preços foram: 50,80;51,10;51,40 e $51,50 \mathrm{~cm}$. Deve-se, entretanto, observar que os espaçamentos ótimos estão um pouco fora do máximo utilizado na montagem do experimento para todas as relações de preços. Assim, sugere-se a implantação de novos experimentos utilizando-se espaçamentos maiores entre linhas, para verificar se estes resultados são ou não confirmados. 


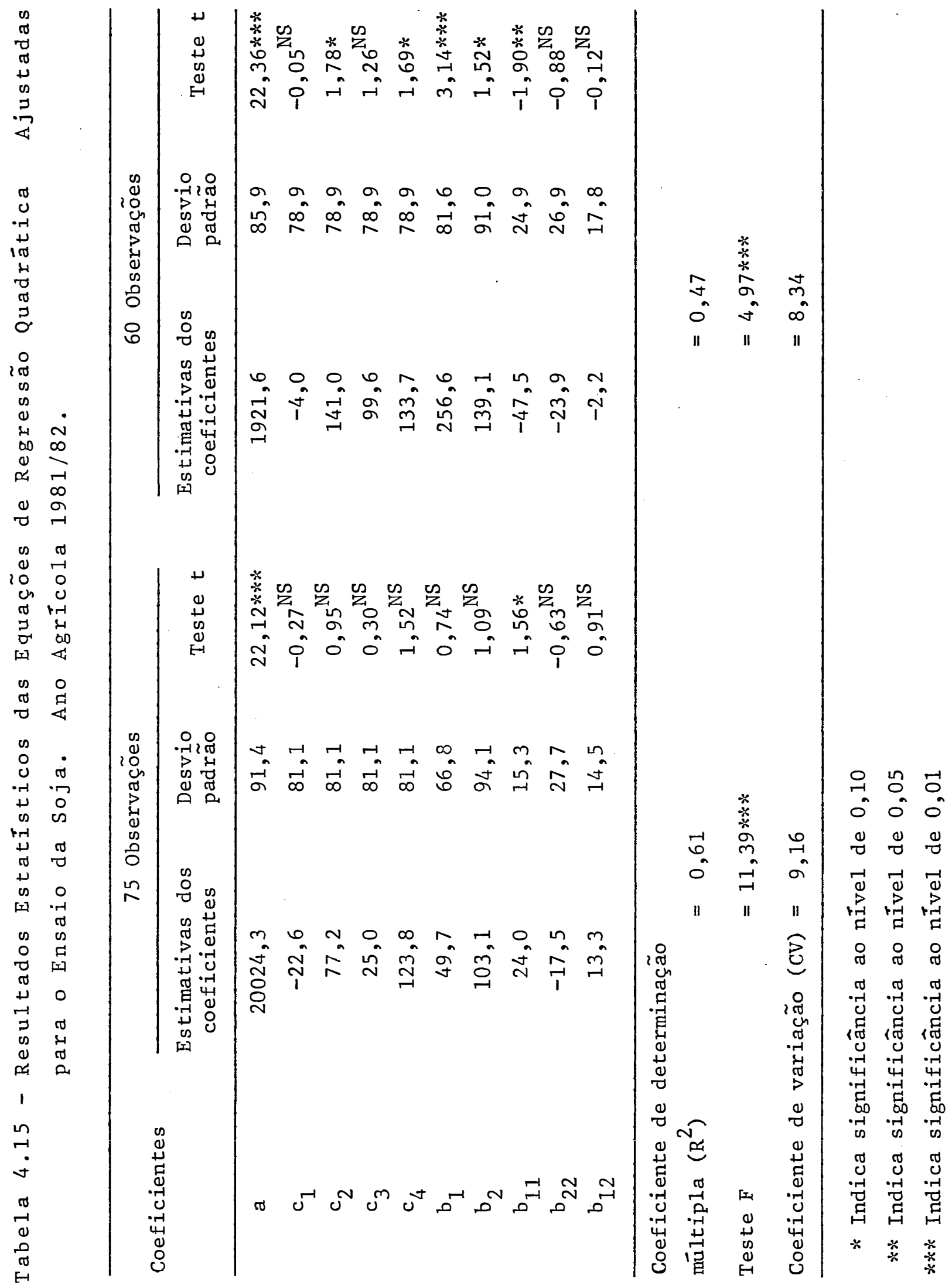


Tabela 4.16-Estimativas dos Parâmetros das Equações de Regres são Quadrática Ajustadas para o Ensaio da Soja Fósforo. Ano Agrícola 1981/82.

\begin{tabular}{llll}
\hline Coeficientes & $\begin{array}{c}\text { Estimativas dos } \\
\text { coeficientes }\end{array}$ & $\begin{array}{l}\text { Desvio } \\
\text { Padrão }\end{array}$ & Teste t
\end{tabular}

75 observações

\begin{tabular}{cccc}
\hline $\mathrm{a}$ & 2144,2 & 50,1 & $42,73^{* * *}$ \\
$\mathrm{~b}_{1}$ & 1,68 & 1,486 & $1,13^{\mathrm{NS}}$ \\
$\mathrm{b}_{11}$ & 0,015 & 0,008 & $1,68^{* *}$ \\
\hline
\end{tabular}

Coeficiente de determinação $\left(R^{2}\right)=0,50$

Teste $F=36,01^{* * *}$

60 observações

$\begin{array}{lccc}\mathrm{a} & 2101,2 & 49,9 & 42,05^{* \cdots *} \\ \mathrm{~b}_{1} & 6,34 & 2,00 & 3,16^{* * *} \\ \mathrm{~b}_{11} & -0,0297 & 0,01 & -1,85^{* * *}\end{array}$

Coeficiente de determinação $\left(R^{2}\right)=0,29$

Teste $F=12,17 * * *$ 
Tabela 4.17-Estimativas dos Parâmetros das Equações de Regres são Raiz Quadrada Ajustadas para o Ensaio da Soja - Fósforo. Ano Agrícola 1981/82.

\begin{tabular}{|c|c|c|c|}
\hline Coeficientes & $\begin{array}{c}\text { Estimativas dos } \\
\text { coeficientes }\end{array}$ & $\begin{array}{l}\text { Desvio } \\
\text { padrão }\end{array}$ & Teste $t$ \\
\hline \multicolumn{4}{|c|}{75 Observações } \\
\hline a & 2108,0 & 53,0 & $39,75^{* * *}$ \\
\hline $\mathrm{b}_{1}$ & 4,59 & 1,45 & $3,15 * \div *$ \\
\hline $\mathrm{b}_{2}$ & $-6,66$ & 18,59 & $-0,35^{N S}$ \\
\hline
\end{tabular}

Coeficiente de determinação $\left(R^{2}\right)=0,48$

Teste $F=34,05 * * *$

60 observações

\begin{tabular}{crrr}
$\mathrm{a}$ & 2091,6 & 51,1 & $40,87^{* * *}$ \\
$\mathrm{~b}_{1}$ & $-1,33$ & 2,08 & $-0,63^{\mathrm{NS}}$ \\
$\mathrm{b}_{2}$ & 46,31 & 22,62 & $2,04 * *$ \\
\hline
\end{tabular}

Coeficiente de determinação $\left(R^{2}\right)=0,30$

Teste $F=12,66 \% *$ 
Tabela 4.18-Estimativas dos Parâmetros das Equações de Regres são Mitscherlich Ajustadas para o Ensaio da Soja - Fósforo. Ano Agrícola 1981/82.

Coeficientes

Estimativas dos coeficientes

\section{Desvio}

padrão

Teste $t$

60 observações

$\begin{array}{cccc}\text { a } & 2444,7 & 67,5 & 36,17 * * * \\ \text { d } & 69,18 & 41,23 & 1,67 * \\ \text { c } & 0,01215 & 0,00781 & 1,55 *\end{array}$

Coeficiente de determinação $\left(R^{2}\right)=0,30$

Teste $F=12,56 * * *$ 


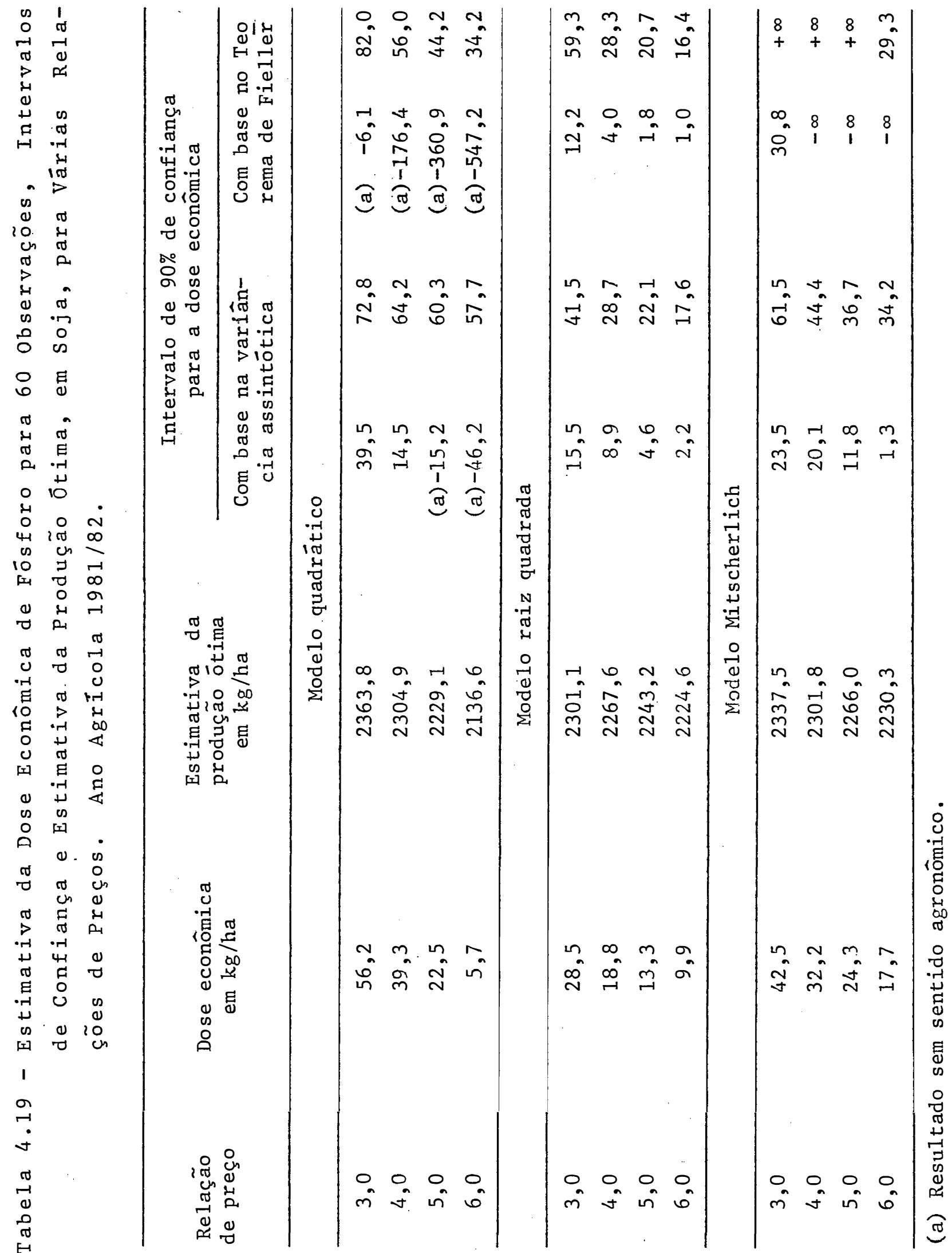


5. CONCLUSÕES

5.1. Considerações sobre a Implantação dos Ensaios de Adub ação

Devido à importância de se realizar uma anālise econômica nos experimentos de adubação, os pesquisadores devem planejā-los de tal modo que os seus resultados possam ser submetidos a uma avaliação econômica.

Portanto, antes de implantar tais experimentos, os pesquisadores devem obter anālise química do solo a ser estudado. Com base nessas informações, deve-se estabelecer as doses de nutrientes a serem utilizadas no experimento de tal maneira que a dose economicamente ótima seja uma interpolação entre aquelas doses. O tipo de delineamento a ser utilizado deve possibilitar tanto a anāise estatística como a anālise econômica dos resultados. Deste modo, os cientistas de solo e economistas devem trabalhar juntos no planejamento dos delinea mentos experimentais e, para que se possa fazer recomendação 
com maior segurança, deve-se repetir os experimentos em mais de um lugar durante vários anos.

5.2. Conclusões Relativas aos Resultados Obtidos nos Experi mentos de Milho e Soja

5.2.1. Mi1ho

Os resultados obtidos para as doses econômicas de nitrogênio para o ensaio 1 são mais concordantes entre os mode los raiz quadrada e Mitscherlich do que para o modelo quadráti co. Entretanto, os intervalos deconfiança para os três modelos estudados são muito amplos, não permitindo indicar dose ótima econômica confiāvel.

Para o nitrogênio no ensaio 2 , os intervalos de confiança baseados na Variância Assintótica e no Teorema de Fieller são bem semelhantes e com uma pequena amplitude, poden do-se mesmo indicar para esse caso $35 \mathrm{~kg} / \mathrm{ha} \mathrm{de}$.

As doses economicamente ótimas de fósforo obtidas no ensaio 2 para os três modelos estudados não apresentam resultados similares. Para os modelos quadrático e Mitscherlich o critério razoável seria recomendar não adubar.

Para o potásio, nos dois modelos analisados, os intervalos de confiança foram bem discrepantes e de uma grande amplitude, não permitindo indicar uma dose ótima. 
No modelo raiz quadrada o limite inferior do intervalo de confiança baseado na Variância Assintótica não se comportou de acordo com a Lei dos Rendimentos Marginais Decres centes, isto é,cresceu quando se aumentou a relação de preços na determinação das doses econômicas de nitrogênio para o ensaio 1 e de fósforo para o ensaio 2.

o limite superior do intervalo de confiança baseado na Variância Assintótica, cresceu quando se aumentou a relação de preços na determinação das doses econômicas de. nitrogênio para o ensaio 1 e de fósforo e potássio para o ensaio 2 .

Ao compararmos as quantidades ótimas econômicas de $N, P$ e K obtidas com as estimativas das superfícies de produção quadrática, com as obtidas quando se ajustou uma função quadrática para cada nutriente, verifica-se que, para as mesmas relações de preços consideradas os resultados não foram se melhantes: $68,4(58,9) \mathrm{kg} / \mathrm{ha} \mathrm{de} \mathrm{N} ;-32,1(-42,3) \mathrm{kg} / \mathrm{ha}$ de $\mathrm{P}_{2} \mathrm{O}_{5}$ e $77,9(56,2) \mathrm{kg} / \mathrm{ha}$ de $\mathrm{K}_{2} 0$. Isto se deve aos efeitos de interação entre os nutrientes, apesar de as interações serem estatisticamente não-significantes.

\section{2 .2 . Soja}

Para o fósforo, no modelo raiz quadrada, os intervalos de confiança baseados na Variância Assintótica e no Teorema de Fieller são bem semelhantes e de uma amplitude rela 
tivamente pequena podendo-se indicar como dose ótima de fósforo para menor relação de preços, $28 \mathrm{~kg} / \mathrm{ha}$ de $\mathrm{P}_{2} \mathrm{O}_{5}$.

Comparando as quantidades ótimas econômicas de fósforo obtidas com base na superfície de produção quadrātica, com aquelas baseadas em funções quadrāticas estimadas separada mente para o nutriente, verifica-se que, para todas as relações de preços consideradas, os resultados foram semelhantes: $54,4(56,2) ; 37,6(39,3) ; 21,6(22,5)$ e $4,0(5,7) \mathrm{kg} / \mathrm{hade} \mathrm{P}_{2} \mathrm{O}_{5^{\circ}}$ Os espaçamentos ótimos encontrados para a soja $(51,25 ; 51,30 ; 51,40$ e $51,50 \mathrm{~cm})$ estão além dos 1 imites usados nos experimentos. Assim, sugere-se a implantação de novos experimentos utilizando-se espaçamentos maiores entre linhas para verificar se estes resultados são ou não confirmados.

\subsubsection{Conclusões gerais}

Quando se considera a amplitude dos intervalos de confiança baseados na Variância Assintótica e no Teorema de Fieller, para as doses econômicas de $\mathrm{N}, \mathrm{P}$ e K para a cultura de milho e de $P$ para a cultura da soja, chegamos à conclusão que, para o modelo raiz quadrada é bem menor quando comparado com os modelos quadrātico e Mitscherlich. Em outras palavras, desses três modelos estudados é o modelo raiz quadrada que con duz a uma estimativa da dose econômica menos imprecisa.

Os intervalos de confiança para as doses econômi cas dos nutrientes nas culturas de milho e soja, com base na 
Variância Assintótica e no Teorema de Fieller na maioria dos casos foram bem discrepantes.

A mā qualidade dos ajustamentos obtidos mostra a impossibilidade de se fazer uma recomendação geral para todos os nutrientes nas culturas de milho e soja, com base nos experimentos realizados. 
6. LITERATURA CITADA

BAHIA, F.; R.MAGNAVACA; H.L.dos SANTOS; J.SILVA; A.F.C. BAHIA FILHO; G.E. de FRANCA; A.M.MURAD;A.A.de MACEDO; T.SILVA e E.CUNHA, 1973. Ensaios de Adubação com N, P e K na Cultura de Milho em Minas Gerais. Anālise pela Lei de Mitscherlich. Pesquisa Agropecuāria Brasileira, Série Agronômica. Brasí1 ia, $8: 321-338$.

BRAGA, J.M.; B.V.DEFELIPO e D.O.ANDRADE, 1972. Adubação da So ja em Solos sob Vegetação de Cerrado na Região do Triângulo Mineiro. Revista Ceres. Viçosa, 19(101):52-62.

BRITO, D.P.S.; A.F.de CASTRO; C.NERY e F.A.COSTA, 1971. Ensaio de Adubação de Milho em Latossol Vermelho Amarelo sob Vegetação de Cerrado. Pesquisa Agropecuāria Brasileira, Série Agronômica. Brasília, 6:203-207.

CAMPos, H., 1967. Aspectos de Aplicação das Superfícies de Res postas a Ensaios Fatoriais $3^{3}$ de Adubação. Piracicaba, ESALQ/USP. Tese de Livre Docência, p.43. 
CAMPOS, H. e P.F.C. de ARAUJO, 1971. Aspectos Econômicos da Adubação em Mílho. Agricultura em São Paulo. São Paulo, IEA, Tomo I e II:149-184.

DUTRA, L.G.; J.PEREIRA; J.M.BRAGA e A.S.REGO, 1975. Efeito da Adubação Nitrogenada, Fosfatada e Potássica, na Produção de Soja (Glycine max (L.) Merril) e do Feijão (Phaseolus vulga ris L.) em Latossol Vermelho Escuro. Textura Média nos municípios de Goiânia e Anāpolis, Goiās. Revista Ceres. Viçosa, $22(123): 341-358$.

FREITAS, F.G. e C.O.SILVEIRA, 1977. Principais Solos sob Vege tação de Cerrado e sua Aptidão Agrícola. In: FERRI, M.G., Coord. IV Simpósio sobre o Cerrado: bases para utilização agropecuária. Belo Horizontes, Ed.Itatiaia São Paulo, Ed.da Universidade de São Paulo, p.155-194.

GUAZELLI, R.J.; J.F.MENDES; G.R.BAUWIN e S.F.MILLER, 1973 . Efe tos Agronômicos e Econômicos do Calcário, Nitrogênio, Fósfó ro, Potássio, Enxofre e Micronutrientes nos Rendimentos de Soja, Feijão e Arroz em Uberaba, M.G. Pesquisa Agropecuāria Brasileira, Série Agronômica. Brasília, 8(6):29-37.

HOFFMANN, R. e S.VIEIRA, 1976. Determinação do Intervalo de Confiança para a Dose Econômica de Nutriente com Base em Ex perimentos de Adubação. Série Pesquisa nọ 35. ESALQ/USP, Piracicaba. 61 p. 
HOFFMAN, R. e S.VIEIRA, 1977. Anālise de Regressão: uma Introdução à Econometria. São Paulo, Ed.HUCITEC. 339 p. Co leção Economia e Planejamento.

IPEA, 1973. Aproveitamento Atual e Potencial dos Cerrados. Bra sília, vol. 1, $197 \mathrm{p}$.

INSTITUTO DE ECONOMIA AgRICOLA/SECRETARIA DA AGRICULTURA, 1982. Prognóstico 82/83. São Paulo p. 140.

KUSSOW, W.R.; K.R.CORUM e F.M.DALL'ACQUA, 1976. Interpretação Agro-Econômica de Ensaios de Adubação. Boletim Técnico nọ 4, C.N.P.A.F. - Goiânia, 49 p.

LOBATO, E.; W.V.SOARES; E.W.FRANCIS e J.D.DOWNES, 1978. A Aná lise Econômica de Experimentos de Adubação de Milho e Soja em Solos de Cerrado do Distrito Federal. Soja - Resumos In formaticos. EMBRAPA, vol 2 p. 182.

MASCARENHAS, H.A.A.; J.D.DEMATTÊ; S.MIYASADA e T.IGUE, 1971. Es tudos Preliminares sobre a Adubação Econômica da Soja (Glycine $\max (\mathrm{L}$.$) Merril), na Região da Alta Mogiana, em Latos-$ sol Roxo e Latossol Vermelho Escuro fase Arenosa. Campinas: Secretaria da Agricultura, IAC, Projeto BNDE/ANDA/CIA, no 3 . MIRANDA, C.N.; J.MIQNICZVK e E.LOBATO, 1980. Calagem e Adubação Corretiva. In: MARCheTtI, D. e A.D.MACHAdo, Coord. V Simpósio sobre o Cerrado: Uso e Manejo. Brasilia, Ed.Terra p. 521-578. 
PIMENTEL GOMES, F., 1982. Curso de Estatística Experimenta1. São Paulo, Livraria Nobel, Ed.Distribuidora 10ạ edição, 430p. EMBRAPA/CPAC, 1976. Relatório Técnico Anual. Brasília, 150 p. SATURNINO, M.A.C. e F.MORENO, 1977. Avaliação dos Retornos e Riscos Relacionados ao Uso de Fósforo e Cálcio em Soja na Região de Cerrado de Minas Gerais. Revista de Economia Rura1. Brasí1ia, $15(1): 209-234$.

SCHUH, G.E. e H.TOLLINI, 1972. Anālise Econômica de Ensaios de Adubação. Trabalho preliminar, EAPA/SUPLAN do Ministério da Agricultura, Brasília $44 \mathrm{p}$.

SCOLARI, D.D.G.; E.LOBATO e J.C.A.J.MAGALHÃES, 1982 . Um Estudo Econômico sobre Fósforo e Calcário em Solos de Cerrado do Brasil. Pesquisa Agropecuāria Brasileira. Brasília. Vol. 7 (4) 505-511.

VIEIRA, S., 1980. Estudo Econométrico de Função de Produção para Adubação. Ciência e Cultura, vol 32 (3) p.343.

WRIGHT, C.L., 1973. Anāiise Econômica de Adubação em Culturas Anuais na Região de Ribeirão Preto Ano Agrícola 1971/72. Pi racicaba, ESALQ/USP 162 p. (Tese de Mestrado)

ZAGATTO, A.G. e F.PIMENTEL GOMES, 1967. Aspectos Econômicos da Adubação. Capítulo do livro Manual de Química Agrícola, 2a edição por MALAVolta et aliii, Ed. Agronômica Ceres, são Pau $10 \quad 560-580 \mathrm{p}$ 